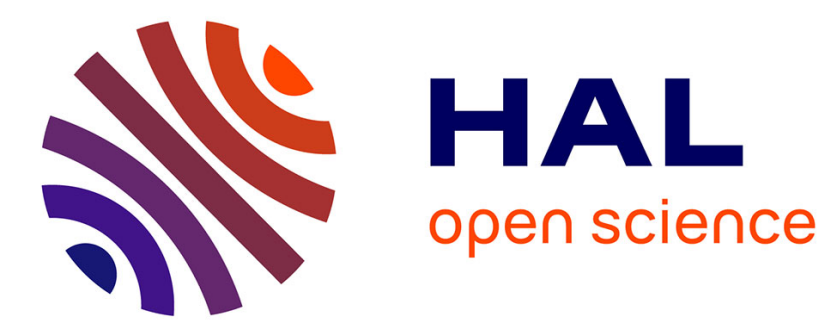

\title{
Design of polysaccharide-b-elastin like polypeptide bioconjugates and their thermoresponsive self-assembly
}

Ye Xiao, Zoeisha Chinoy, Gilles Pécastaings, Katell Bathany, Elisabeth

Garanger, Sébastien Lecommandoux

\section{- To cite this version:}

Ye Xiao, Zoeisha Chinoy, Gilles Pécastaings, Katell Bathany, Elisabeth Garanger, et al.. Design of polysaccharide-b-elastin like polypeptide bioconjugates and their thermoresponsive self-assembly. Biomacromolecules, 2020, 21 (1), pp.114-125. 10.1021/acs.biomac.9b01058 . hal-02299856

\section{HAL Id: hal-02299856 https://hal.science/hal-02299856}

Submitted on 13 Mar 2020

HAL is a multi-disciplinary open access archive for the deposit and dissemination of scientific research documents, whether they are published or not. The documents may come from teaching and research institutions in France or abroad, or from public or private research centers.
L'archive ouverte pluridisciplinaire HAL, est destinée au dépôt et à la diffusion de documents scientifiques de niveau recherche, publiés ou non, émanant des établissements d'enseignement et de recherche français ou étrangers, des laboratoires publics ou privés. 


\section{Design of polysaccharide- $b$-elastin like polypeptide}

\section{bioconjugates and their thermoresponsive self-}

\section{assembly}

Ye Xiao ${ }^{\dagger \xi}$ Zoeisha S. Chinoy, ${ }^{\dagger \$}$ Gilles Pecastaings, ${ }^{\dagger}$ Katell Bathany, ${ }^{\dagger}$ Elisabeth Garanger, ${ }^{* \dagger}$ and Sébastien Lecommandoux ${ }^{* \dagger}$

$\dagger$ Univ. Bordeaux, CNRS, Bordeaux INP, LCPO, UMR 5629, F-33600, Pessac, France

$\$$ Univ. Bordeaux, CNRS, Bordeaux INP, Chimie et Biologie des Membranes et des Nano-objets

(UMR 5248), Allée Geoffroy Saint Hilaire, F-33600, Pessac, France

$\S$ Authors contributed equally to this work 


\section{ABSTRACT}

The advantageous biological properties of polysaccharides and precise stimuli-responsiveness of elastin-like polypeptides (ELPs) are of great interest for the design of polysaccharide and polypeptide-based amphiphilic block copolymers for biomedical applications. Herein, we report the synthesis and characterization of a series of polysaccharide-block-ELP copolymers, containing two biocompatible and biodegradable blocks coupled via copper(I)-catalyzed azidealkyne cycloaddition (CuAAC). The resulting bioconjugates are capable of self-assembling into well-defined nanoparticles in aqueous solution upon raising the solution temperature above a specific transition temperature $\left(T_{\mathrm{t}}\right)$ - a characteristic of the ELP moiety. To the best of our knowledge, this is the first study where polysaccharides were combined with a stimuliresponsive ELP for the preparation of thermo-sensitive self-assemblies, providing insight into novel pathways for designing bioinspired stimuli-responsive self-assemblies for biomedical applications.

\section{INTRODUCTION}

Nanostructured carriers resulting from the self-assembly of amphiphilic block copolymers have been developed for a broad range of applications, ranging from biomimetics ${ }^{1-3}$ to nanomedicines. ${ }^{4,5}$ Numerous synthetic polymers have been selected as building blocks due to their biocompatibility and low cytotoxicity, such as poly(ethylene glycol), ${ }^{6,7}$ poly(L-glutamic acid), ${ }^{8,9}$ poly( $\gamma$-benzyl-L-glutamate),${ }^{10-12}$ poly(2-hydroxyethyl methacrylate),${ }^{13,14}$ polylactide, ${ }^{15,16}$ polycaprolactone, ${ }^{17}$ and poly(trimethylene carbonate), ${ }^{9,18}$ and have been approved for biomedical applications by regulatory agencies. Additionally, biologically derived or inspired polymers, like polysaccharides $^{19-21}$ and polypeptides ${ }^{22}$, show considerable promise as block copolymer 
constructs since they are naturally biodegradable, biocompatible and are potentially biofunctional. Regarding the biomedical application of block copolymers as carriers, a key challenge is to enhance accumulation of the active components at the biological target. ${ }^{23} \mathrm{~A}$ typical method to achieve this goal is to introduce bioactive targeting moieties on the surface of nano-objects. ${ }^{24-26}$ Such surface decorated strategies have led to the design of original bioactive block copolymers that favor the use of natural targeting functionalities. ${ }^{27-29}$ In this respect, bioactive polysaccharides-based (e.g., chitosan, ${ }^{30,31}$ galactan, ${ }^{32}$ fucoidan, ${ }^{33}$ hyaluronan ${ }^{11,34}$ ) block copolymers able to recognize and bind to specific receptors demonstrate particularly promising interest for potential biomedical applications. ${ }^{35}$

Recently, stimuli-responsive polymer nanosystems ${ }^{36-41}$ have been extensively explored due to their ability of supramolecular assembly or disassembly in response to "internal stimuli", such as $\mathrm{pH}^{42,43}$ reductive-oxidative environment ${ }^{44,45}$ and enzymes, ${ }^{46}$ or "external stimuli", such as temperature, $^{47,48}$ light $^{49,50}$ and magnetic field ${ }^{51}$. Among them, recombinant elastin-like polypeptides (ELPs) have gained significant attention as stimuli-responsive protein-like polymers. ${ }^{52-54}$ In aqueous solution, ELPs display a lower critical solution temperature (LCST), similar to synthetic thermo-responsive polymers such as poly( $N$-isopropyl acrylamide) PNIPAM, ${ }^{55}$ also referred to as inverse transition temperature $\left(T_{\mathrm{t}}\right)$ that actually corresponds to the cloud point temperature. Below the $T_{\mathrm{t}}$, ELPs are water soluble, while upon heating the solution temperature above the $T_{\mathrm{t}}$, ELPs aggregate into insoluble coacervates, this phase transition being fully reversible. $T_{\mathrm{t}}$ can be highly tunable either by playing with molecular parameters such as varying amino acid residues composition and protein molecular weight, or by controlling environmental parameters such as concentration, $\mathrm{pH}$ or cosolutes. ${ }^{56-58}$ Post-translational chemical modification of ELPs, for example, chemoselective modifications of ELPs at the $C$ - or $N$ - 
terminal end, ${ }^{59}$ or at specific residues such as methionine,${ }^{60-62}$ cysteine,${ }^{63,64}$ tyrosine, ${ }^{65}$ or lysine ${ }^{66,67}$ has also been exploited for tuning the $T_{\mathrm{t}}$ of specific ELPs, as well as for facilitating subsequent conjugation of ELPs with polymers, ${ }^{59,66}$ dyes, ${ }^{64}$ or drugs ${ }^{67,68}$. ELP diblock copolymers could be obtained by fusing ELP blocks with different $T_{\mathrm{t}}$, which self-assembled into micelles by triggering the phase transition of the ELP block with the lowest $T_{\mathrm{t}}{ }^{69-72}$ The stimuliresponsive property of ELPs has also been exploited to obtain well-defined ELP-based nanomedicines, such as ELP-proteins, ${ }^{73}$ ELP-drug conjugates, ${ }^{67}$ and ELP-nucleic acid complexes. ${ }^{74}$ Moreover, as a building block of copolymers, combinations of ELPs with other types of polymer-based blocks, such as poly $(\gamma$-benzyl-L-glutamate) $),{ }^{75}$ poly(L-glutamic acid) ${ }^{8}$ poly(aspartic acid), ${ }^{76}$ poly(ethylene glycol), ${ }^{59,77}$ and polyelectrolyte ${ }^{78}$ has demonstrated to be a fascinating strategy to obtain functional block copolymers which could self-assemble in aqueous conditions above a specific and tunable $T_{\mathrm{t}}$.

Although polysaccharides and polypeptides-based block copolymers were reported for decades, benefits from conjugates of polysaccharides with ELPs have not yet been investigated, since a highly efficient and proper conjugation method is required. We previously synthesized polysaccharide-b-polypeptide block copolymers via copper(I)-catalyzed azide-alkyne cycloaddition (CuAAC) for the preparation of glycoprotein biomimetic vesicles, ${ }^{11,12}$ and demonstrated the interest of such design as drug-delivery nanocarriers. ${ }^{79,80}$ To be able to use CuAAC "click" chemistry for conjugation, polysaccharides and ELPs need to be functionalized with either an azide or an alkyne group. ${ }^{81}$ Polysaccharides can be readily modified at the reducing end with azide-containing linkers using reductive amination, ${ }^{11,12}$ or by using bifunctional oxyamine, oxime or $N$-methoxyamine linkers ${ }^{82,83}$. Regarding the introduction of an alkyne group at the ELP chain end, an alkyne functionalized $N$-hydroxysuccinimide ester (NHS- 
ester) can be easily prepared and coupled with the $N$-terminal primary amine group, granting the ELP with a functional moiety to conjugate with the polysaccharide. ${ }^{84}$

We present here, a modular approach that combines polysaccharide and ELP into block copolymers capable of self-assembling into nanoparticles in aqueous solution upon heating above a specific $T_{\mathrm{t}}$. Both block being composed of biological molecules, make the polysaccharide- $b$-ELP bioconjugates biocompatible, biodegradable and possibly bioactive. The versatile choice of polysaccharide and ELP allow "tailor-made" design of bioconjugates for a desired propose, such as specific receptor binding and drug loading. The ELP block can be further modified at methionine residues, allowing subsequent orthogonal biofunctionalization of bioconjugates with small molecules such as dyes or inter-chain cross-linking. Three different polysaccharides namely dextran, ${ }^{10,12}$ laminarihexaose ${ }^{85,86}$ and hyaluronic acid, ${ }^{11,25,34}$ were functionalized with an azide moiety at their reducing end, while the ELP was modified with an alkyne moiety at the $N$-terminus by NHS-coupling chemistry. Three polysaccharide- $b$-ELP bioconjugates were thus prepared through click chemistry, isolated and subsequently fully characterized. Their transition temperature behaviors were studied through turbidity measurements by ultraviolet-visible (UV-Vis) spectroscopy and their self-assembly properties were subsequently investigated by temperature-varying dynamic light scattering (DLS) and temperature-controlled liquid atomic force microscopy (Liquid AFM). To our knowledge, the synthesis and temperature-triggered self-assembly behavior study of polysaccharide- $b$-ELPs block copolymers were demonstrated for the first time, providing insight into original pathways for designing bioactive thermo-sensitive self-assemblies for biomedical applications. 


\section{EXPERIMENTAL SECTION}

\section{Materials}

Acrolein (95\%), sodium azide $\left(\mathrm{NaN}_{3}, 99.5 \%\right)$, acetic acid (AcOH, 99.8\%), methoxylamine hydrochloride (98\%), sodium cyanoborohydride $\left(\mathrm{NaBH}_{3} \mathrm{CN}, 95 \%\right)$, hydrochloric acid ( $\mathrm{HCl}$, 37\%), 4-pentynoic acid (97\%), N,N'-dicyclohexylcarbodiimide $\quad($ DCC, $99 \%), \quad N-$ hydroxysuccinimide (NHS, 98\%), trimethylamine (TEA, 99\%), copper(II) sulfate pentahydrate $\left(\mathrm{CuSO}_{4}, 99 \%\right)$, dichloromethane (DCM, 99.9\%), N,N-dimethylformamide (DMF, 99.8\%), dimethyl sulfoxide (DMSO, 99.7\%), methanol (MeOH, 99.8\%), diethyl ether (99.9\%) and anhydrous magnesium sulfate $\left(\mathrm{MgSO}_{4}, 99.5 \%\right)$ were purchased from Sigma-Aldrich. $N, N$ Diisopropylethylamine (DIPEA, 99\%), sodium acetate (AcONa, 99\%) and sodium ascorbate (NaAsc, 99\%) were obtained from Alfa Aesar. Tris(benzyltriazolylmethyl)amine (TBTA, 97\%) were purchased from TCI. Cuprisorb ${ }^{\circledR}$ was purchased from Seachem. Dextran (Dex, T10) was purchased from pharmacosmos. Laminarihexaose (Lam) was purchased from Megazyme. Sodium hyaluronate (HA) was purchased from Lifecore Biomedical. Water was purified using an ELGA PURELAB Classic system. Solvent was purified using PureSolv MD-5 solvent purification system from Innovative Technology. Dialysis was conducted using a Spectra/Por ${ }^{\circledR} 6$ dialysis membrane.

\section{Synthetic Procedure}

Synthesis of N-(3-azidopropyl)-O-methylhydroxylamine (Azide-linker, 1). Acrolein (1.84 mL, $27.4 \mathrm{mmol})$ was added to acetic acid $(4 \mathrm{~mL})$ at $-20{ }^{\circ} \mathrm{C}$, followed by dropwise addition of a solution of sodium azide $(2.38 \mathrm{~g}, 41.2 \mathrm{mmol})$ in $\mathrm{H}_{2} \mathrm{O}(10.4 \mathrm{~mL})$. The reaction mixture was let to stir at $-20{ }^{\circ} \mathrm{C}$ for 1.5 hour. It was then quenched with a saturated solution of $\mathrm{NaHCO}_{3}(80 \mathrm{~mL})$ 
and the resulting mixture was extracted with DCM $(2 \times 100 \mathrm{~mL})$. The combined organic extracts were washed with sat. aq. $\mathrm{NaHCO}_{3}(150 \mathrm{~mL})$, dried over $\mathrm{MgSO}_{4}$, filtered and concentrated in vacuo to $100 \mathrm{~mL}$. To the solution in DCM, methoxylamine hydrochloride (2.68 $\mathrm{g}, 31.68 \mathrm{mmol})$ and sodium acetate (4.42 $\mathrm{g}, 54 \mathrm{mmol})$ were added and the mixture was stirred overnight at r.t. Sat. aq. $\mathrm{NaHCO}_{3}(150 \mathrm{~mL})$ was added to quench the reaction and the resulting mixture was then extracted with DCM $(2 \times 100 \mathrm{~mL})$. The combined organic extracts were washed with Sat. aq. $\mathrm{NaHCO}_{3}(150 \mathrm{~mL})$, dried over $\mathrm{MgSO}_{4}$, filtered and concentrated in vacuo to $100 \mathrm{~mL}$. To the solution in $\mathrm{DCM}, \mathrm{NaBH}_{3} \mathrm{CN}(2 \mathrm{~g}, 32 \mathrm{mmol})$ was added, followed by dropwise addition of $1 \mathrm{M}$ ethanolic $\mathrm{HCl}$ (32 $\mathrm{mL}$, freshly prepared by adding acetyl chloride to ethanol). The reaction mixture was stirred at r.t for 1.5 hour, concentrated and the resulting white solid suspended in sat. aq. $\mathrm{NaHCO}_{3}(150 \mathrm{~mL})$ and extracted with $\mathrm{DCM}(2 \times 100 \mathrm{~mL})$. The combined organic extracts were washed with sat. aq. $\mathrm{NaHCO}_{3}(150 \mathrm{~mL})$, dried over $\mathrm{MgSO}_{4}$, filtered and concentrated in vacuo to afford the crude $\mathrm{N}$-(3-azidopropyl)-O-methylhydroxylamine as a yellow oil. Purification of the crude product by silica gel column chromatography $(1-3 \% \mathrm{MeOH}$ in DCM) yielded $\mathrm{N}$-(3-azidopropyl)-O-methylhydroxylamine as a colorless oil (Azide-linker, $2.2 \mathrm{~g}$, $62 \%$ over 3 steps). ${ }^{1} \mathrm{H}$ NMR (400 MHz, $\left.\mathrm{CDCl}_{3}\right): \delta 3.55\left(\mathrm{~s}, 3 \mathrm{H}, \mathrm{CH}_{3} \mathrm{O}\right), 3.41\left(\mathrm{t}, 2 \mathrm{H}, \mathrm{CH}_{2} \mathrm{~N}_{3}\right), 3.00$ (t, 2H, $\left.\mathrm{NHCH}_{2}\right), 1.83\left(\mathrm{p}, 2 \mathrm{H}, \mathrm{CH}_{2} \mathrm{CH}_{2} \mathrm{CH}_{2}\right) .{ }^{13} \mathrm{C} \mathrm{NMR}\left(101 \mathrm{MHz}, \mathrm{CDCl}_{3}\right): \delta 62.01\left(\mathrm{CH}_{3} \mathrm{O}\right)$, $49.44\left(\mathrm{CH}_{2} \mathrm{~N}_{3}\right), 48.94\left(\mathrm{NHCH}_{2}\right), 26.87\left(\mathrm{CH}_{2} \mathrm{CH}_{2} \mathrm{CH}_{2}\right)$. In agreement with the literature data. ${ }^{82}$

Synthesis of Dextran-Azide (Dex- $\left.\boldsymbol{N}_{3}, 2\right)$. The azide-linker (380 mg, $\left.2.9 \mathrm{mmol}\right)$ was added to a solution of dextran $(\mathrm{MW}=8,000 \mathrm{Da}, 1 \mathrm{~g}, 125 \mu \mathrm{mol})$ in acetate buffer $(\mathrm{AcOH} / \mathrm{AcONa}, 2 \mathrm{M}, \mathrm{pH}$ 4.6, $4.2 \mathrm{~mL}$ ), and the reaction mixture was incubated at $40{ }^{\circ} \mathrm{C}$ with shaking, for 9 days. The product was purified by dialysis (dialysis bag MWCO $1 \mathrm{kDa}$ ) against pure water for 24 hour (changing water 3 times per day), followed by lyophilization to obtain the product as a white 
powder (805 mg, 79\% yield). ${ }^{1} \mathrm{H}$ NMR (400 MHz, $\left.\mathrm{D}_{2} \mathrm{O}\right): \delta 4.98(\mathrm{~d}, \mathrm{H}-1), 4.18(\mathrm{~d}$, $\left.\mathrm{CHN}\left(\mathrm{OCH}_{3}\right) \mathrm{CH}_{2}\right)$, 4.04-3.97 (m, H-6), 3.95-3.89 (m, H-5), 3.69-3.80 (br m, H-6', H-3), 3.613.37 (br m, H-2, H-4, $\left.\mathrm{CH}_{2} \mathrm{~N}_{3}\right), \quad 3.20-3.13$ (dt, $\left.\mathrm{CHN}\left(\mathrm{OCH}_{3}\right) \mathrm{CH}_{2}\right), \quad 3.01-2.93$ (dt, $\mathrm{CHN}\left(\mathrm{OCH}_{3}\right) \mathrm{CH}_{2}$ ) $)$ 1.92-1.88 (m, $\left.\mathrm{CH}_{2} \mathrm{CH}_{2} \mathrm{CH}_{2}\right)$. FT-IR (ATR): 3368, 2906, 2106 (vazide), 1351, $1148,1164,1007,915,846,763,545,429 \mathrm{~cm}^{-1}$.

Synthesis of Laminarihexaose-Azide (Lam-N33, 3). The azide-linker (900 mg, 6.9 mmol) was added to a solution of laminarihexaose $(500 \mathrm{mg}, 0.5 \mathrm{mmol})$ in acetate buffer ( $\mathrm{AcOH} / \mathrm{AcONa}, 2$ $\mathrm{M}, \mathrm{pH} 4.6,5 \mathrm{~mL}$ ), and the reaction mixture incubated at $40{ }^{\circ} \mathrm{C}$ with shaking, for 8 days (vortexing 3 times per day). Then the mixture was lyophilized and re-dissolved in water $5 \mathrm{~mL}$, purified by dialysis (dialysis bag MWCO $100 \mathrm{Da}$ ) against pure water for 3 days (changing water 3 times per day and transferring excess dialysis solution to new dialysis bag every 12 hour), followed by lyophilization to obtain the product as a white powder $(302 \mathrm{mg}, 54 \%$ yield $) .{ }^{1} \mathrm{H}$ NMR (400 MHz, D $2 \mathrm{O}): \delta 4.81(\mathrm{~d}, \mathrm{H}-1), 4.23\left(\mathrm{~m}, \mathrm{CHN}\left(\mathrm{OCH}_{3}\right) \mathrm{CH}_{2}\right), 3.97-3.88$ (m, H-6), 3.863.68 (br m, H-6',H-3), 3.67-3.33 (br m, H-2,H-4,H-5, $\mathrm{CH}_{2} \mathrm{~N}_{3}$ ), 3.22-3.13 (m, $\mathrm{CHN}\left(\mathrm{OCH}_{3}\right) \mathrm{CH}_{2}$ ), 3.03-2.95 (m, $\left.\mathrm{CHN}\left(\mathrm{OCH}_{3}\right) \mathrm{CH}_{2}\right), 1.91$ (m, $\left.\mathrm{CH}_{2} \mathrm{CH}_{2} \mathrm{CH}_{2}\right)$. FT-IR (ATR): 3434, 3151, 2890, 2100 ( $\left.v_{\text {azide }}\right), 1568,1403,1308,1159,1072,1022,896,557 \mathrm{~cm}^{-1}$.

Synthesis of Hyaluronan-Azide (HA-N ${ }_{3}$, 4). The azide-linker (520 mg, $\left.4 \mathrm{mmol}\right)$ and sodium cyanoborohydride $(65 \mathrm{mg}, 1 \mathrm{mmol})$ were added to a solution of sodium hyaluronate $(\mathrm{MW}=$ 7,000 Da, $1 \mathrm{~g}, 0.14 \mathrm{mmol})$ in acetate buffer $(\mathrm{AcOH} / \mathrm{AcONa}, 2 \mathrm{M}, \mathrm{pH} 5.5,5 \mathrm{~mL})$, and the reaction mixture was incubated at $50{ }^{\circ} \mathrm{C}$ with shaking, for 5 days. The product was purified by dialysis (dialysis bag MWCO $1 \mathrm{kDa}$ ) against pure water for 24 hour (changing water 3 times per day), followed by lyophilization to obtain the product as a white powder. (610 $\mathrm{mg}, 60 \%$ yield). ${ }^{1} \mathrm{H}$ NMR (400 MHz, D $2 \mathrm{O}$ ): $\delta 4.56$ (d, GlcNAc H-1), 4.48 (d, GlcUA H-1), 3.99-3.67 (br m, 
GlcNAc H-6, H-2, H-3, H-5, GlcUA H-4), 3.66-3.41 (br m, GlcNAc H-4, GlcUA H-3, H-5, $\left.\mathrm{CH}_{2} \mathrm{~N}_{3}\right), 3.35$ (t, GlcUA H-2), 2.94-2.86 (m, $\left.\mathrm{CH}_{2} \mathrm{~N}\left(\mathrm{OCH}_{3}\right) \mathrm{CH}_{2}\right), 2.03$ (s, GlcNAc $\left.\mathrm{COCH}_{3}\right), 1.87$ (m, $\left.\mathrm{CH}_{2} \mathrm{CH}_{2} \mathrm{CH}_{2}\right)$. FT-IR (ATR): 3323, 2892, 2107 (vazide), 1729, 1642, 1555, 1376, 1315, 1152, $1042,610 \mathrm{~cm}^{-1}$.

Synthesis of 4-Pentynoic Acid Succinimidyl Ester (Pentynoic NHS-ester, 5). N, N'dicyclohexylcarbodiimide (480 mg, $2.3 \mathrm{mmol}$ ) was added to a solution of pentynoic acid (210 mg, $2.14 \mathrm{mmol})$ in DCM $(8 \mathrm{~mL})$ and the mixture was stirred at r.t for $5 \mathrm{~min}$ and then $\mathrm{N}$ hydroxysuccinimide (260 mg, $2.3 \mathrm{mmol}$ ) was added. The reaction was continuously stirred at r.t for 3 hour more. Afterwards, the precipitated dicyclohexylurea was filtered over Celite and washed with cold DCM $(2 \times 10 \mathrm{~mL})$. The filtrate was collected and DCM was removed in vacuo. The crude product was re-dissolved in EtOAc $(10 \mathrm{~mL})$ and cooled in a refrigerator at $0{ }^{\circ} \mathrm{C}$ for 20 min. The precipitate was filtered over Celite, and the filtrate was washed with saturated $\mathrm{NaHCO}_{3}$ $(2 \times 50 \mathrm{~mL})$ and brine $(2 \times 50 \mathrm{~mL})$, dried over $\mathrm{MgSO}_{4}$, filtered and concentrated in vacuo to give the crude product as a colorless oil. Purification of the oil by silica gel column chromatography (petroleum ether/EtOAc $=2: 1)$ yielded pentynoic NHS-ester as a white solid $(300 \mathrm{mg}, 72 \%$ yield). ${ }^{1} \mathrm{H}$ NMR (400 MHz, $\left.\mathrm{CDCl}_{3}\right): \delta 2.90-2.82\left(\mathrm{~m}, 6 \mathrm{H}, \mathrm{COCH}_{2} \mathrm{CH}_{2} \mathrm{CO}, \mathrm{OCOCH}_{2} \mathrm{CH}_{2}\right), 2.62$ (ddd, $\left.2 \mathrm{H}, \quad \mathrm{CH}_{2} \mathrm{C} \equiv \mathrm{CH}\right), 2.05(\mathrm{t}, 1 \mathrm{H}, \mathrm{C} \equiv \mathrm{CH}) .{ }^{13} \mathrm{C} \quad \mathrm{NMR} \quad\left(101 \mathrm{MHz}, \mathrm{CDCl}_{3}\right): \delta \quad 168.89$ $\left(\mathrm{COCH}_{2} \mathrm{CH}_{2} \mathrm{CO}\right), 167.02\left(\mathrm{OCOCH}_{2}\right), 80.84\left(\mathrm{CH}_{2} \mathrm{C} \equiv \mathrm{CH}\right), 70.04\left(\mathrm{CH}_{2} \mathrm{C} \equiv \mathrm{CH}\right), 30.31(\mathrm{OCOCH} 2)$, $25.57\left(\mathrm{COCH}_{2} \mathrm{CH}_{2} \mathrm{CO}\right), 14.09\left(\mathrm{CH}_{2} \mathrm{C} \equiv \mathrm{CH}\right)$.

Synthesis of ELP-Alkyne (ELP-Alk, 6). Pentynoic NHS-ester (92 mg, $0.47 \mathrm{mmol}$ ) and N,Ndiisopropylethylamine $(1.7 \mathrm{mg}, 13.2 \mu \mathrm{mol})$ were added to a solution of ELP (MW= 17,035 Da, $225 \mathrm{mg}, 13.2 \mu \mathrm{mol})$ in anhydrous DMSO $(18 \mathrm{~mL})$ and the mixture was stirred at r.t for $72 \mathrm{~h}$. It was then diluted with pure water $(20 \mathrm{~mL})$. The product was purified by dialysis (dialysis bag 
MWCO $15 \mathrm{kDa}$ ) against pure water for $48 \mathrm{~h}$ (changing water 3 times per day), followed by lyophilization to obtain the ELP-Alk as a white powder $\left(210 \mathrm{mg}, 93 \%\right.$ yield). ${ }^{1} \mathrm{H}$ NMR (400 MHz, $\mathrm{D}_{2} \mathrm{O}$ ): $\delta$ 7.63-7.09 (br, indole $H$ Trp), 4.57 (m, $\left.\mathrm{CH}_{\alpha} \mathrm{Met}\right), 4.45$ (m, $\mathrm{CH}_{\alpha}$ Val, Pro), 4.19 (d, $\mathrm{CH}_{\alpha} \mathrm{Val}_{\text {Xaa }}$ ), 4.06-3.89 (br m, $\mathrm{CH}_{2 \alpha}$ Gly, $\mathrm{CH}_{2 \delta}$ Pro), 3.75 (m, $\mathrm{CH}_{2}{ }^{\prime} \delta$ Pro), 2.69-2.46 (br m, $\mathrm{CH}_{2 \gamma}$ Met, $\mathrm{CH}_{2} \mathrm{CH}_{2} \mathrm{C} \equiv \mathrm{CH}$ ), 2.33 (m, $\mathrm{CH}_{2 \beta}$ Pro), 2.18-1.91 (m, $\mathrm{CH}_{2 \beta}$ Met, $\mathrm{CH}_{2}{ }_{\beta}$ Pro, $\mathrm{CH}_{2 \gamma}$ Pro, $\mathrm{CH}_{\beta}$ Val, $\mathrm{CH}_{3 \varepsilon}$ Met, $\left.\mathrm{CH}_{2} \mathrm{C} \equiv \mathrm{CH}\right), 1.05-0.91$ (m, $\mathrm{CH}_{3 \gamma}$ Val). MALDI-TOF: Calculated Mass $=17,115$ Da, Experimental Mass $[\mathrm{M}+\mathrm{H}]^{+}=17,120.5$ Da.

Synthesis of Dextran-b-ELP (Dex-b-ELP, 7). Copper sulfate (6 mg, $22.8 \mu \mathrm{mol}$ ), sodium ascorbate $(10 \mathrm{mg}, 45.6 \mu \mathrm{mol})$ and TBTA $(12 \mathrm{mg}, 22.8 \mu \mathrm{mol})$ were added to a solution of ELPAlk (65 mg, $3.8 \mu \mathrm{mol})$ and Dex-N $3(46 \mathrm{mg}, 5.7 \mu \mathrm{mol})$ in anhydrous DMSO $(8 \mathrm{~mL})$ under argon atmosphere and the reaction mixture was stirred at r.t for 3 days. It was then diluted with cold water $(20 \mathrm{~mL})$ and cooled in a refrigerator at $4{ }^{\circ} \mathrm{C}$ for $20 \mathrm{~min}$. TBTA was precipitated and removed by centrifugation. Cuprisorb $(120 \mathrm{mg})$ was added to the resulting solution and it was then incubated at r.t with shaking, for $18 \mathrm{~h}$ to remove the copper. The solution containing cuprisorb was centrifuged and the supernatant was purified by dialysis (dialysis bag $15 \mathrm{kDa}$ ) against pure water for 5 days (changing water 3 times per day), followed by lyophilization to obtain the product as a white powder (92 mg, $90 \%$ yield). ${ }^{1} \mathrm{H}$ NMR $\left(400 \mathrm{MHz}, \mathrm{D}_{2} \mathrm{O}\right): \delta 7.75$ (s, triazole H), 7.63-7.09 (br, indole $H$ Trp), 4.99 (d, Dex H-1), 4.55 (m, CH $H_{\alpha}$ Met), 4.44 (m, $H_{\alpha}$ Val, Pro), 4.17 (d, $\mathrm{CH}_{\alpha}$ Val $_{\text {Xaa) }}$ ), 4.06-3.87 (br m, $\mathrm{CH}_{2 \alpha}$ Gly, $\mathrm{CH}_{2 \delta}$ Pro, Dex H-6,H-5), 3.82-3.67 (m, $\mathrm{CH}_{2}{ }^{\prime}$ Pro, Dex H-6',H-3), 3.62-3.49 (Dex H-2,H-4), 2.69-2.48 (br m, $\mathrm{CH}_{2 \gamma}$ Met), 2.31 (m, $\mathrm{CH}_{2 \beta}$ Pro), 2.18-1.89 (m, $\mathrm{CH}_{2 \beta}$ Met, $\mathrm{CH}_{2}{ }_{\beta}$ Pro, $\mathrm{CH}_{2 \gamma}$ Pro, $\mathrm{CH}_{\beta}$ Val, $\mathrm{CH}_{3 \varepsilon} \mathrm{Met}$ ), 1.03-0.88 (m, $\mathrm{CH}_{3 \gamma}$ Val). FT-IR (ATR): 3332, 2929, 1653, 1527, 1443, 1342, 1152, 1106, 1017, 917, $547 \mathrm{~cm}^{-1}$. 
Synthesis of Laminarihexaose-b-ELP (Lam-b-ELP, 8). Copper sulfate (5.5 mg, $22 \mu \mathrm{mol})$, sodium ascorbate $(9 \mathrm{mg}, 45.4 \mu \mathrm{mol})$ were added to a solution of ELP-Alk (62 mg, $3.6 \mu \mathrm{mol})$ and Lam-N $3(20 \mathrm{mg}, 18.1 \mu \mathrm{mol})$ in anhydrous DMSO $(8 \mathrm{~mL})$ under argon atmosphere and the reaction mixture was stirred at r.t for 3 days. It was then diluted with cold water $(20 \mathrm{~mL})$, after which Cuprisorb $(110 \mathrm{mg})$ was added and the resulted solution was incubated at r.t with shaking, for overnight to remove the copper. The solution containing cuprisorb was centrifuged and the supernatant was purified by dialysis (dialysis bag MWCO $15 \mathrm{kDa}$ ) against pure water for 5 days (changing water 3 times per day), followed by lyophilization to obtain the product as a white powder (60 mg, 93\% yield). ${ }^{1} \mathrm{H}$ NMR (400 MHz, $\left.\mathrm{D}_{2} \mathrm{O}\right): \delta 7.74$ (s, triazole $\left.\mathrm{H}\right), 7.60-7.09$ (br, indole $H$ Trp), 4.80 (m, Lam H-1), 4.55 (m, CH $H_{\alpha}$ Met), 4.43 (m, CHa Val, Pro), 4.17 (d, $\mathrm{CH}_{\alpha}$ Val $_{\text {Xaa }}$ ), 4.05-3.85 (br m, $\mathrm{CH}_{2 \alpha}$ Gly, $\mathrm{CH}_{2 \delta}$ Pro, Lam H-6), 3.82-3.66 (m, $\mathrm{CH}_{2}{ }^{\prime}$ Pro, Lam H-6',H3), 3.62-3.34 (Lam H-2,H-4, H-5), 2.69-2.48 (br m, $\mathrm{CH}_{2 \gamma}$ Met), 2.41-2.24 (m, $\mathrm{CH}_{2 \beta}$ Pro), 2.191.88 (m, $\mathrm{CH}_{2 \beta}$ Met, $\mathrm{CH}_{2}{ }^{\beta} \beta$ Pro, $\mathrm{CH}_{2 \gamma}$ Pro, $\mathrm{CH}_{\beta}$ Val, $\mathrm{CH}_{3 \varepsilon}$ Met), $1.05-0.85$ (m, $\mathrm{CH}_{3 \gamma}$ Val). FT-IR (ATR): 3322, 2917, 1654, 1522, 1440, 1221, 1105, 1063, 1027, $562 \mathrm{~cm}^{-1}$.

Synthesis of Hyaluronan-b-ELP (HA-b-ELP, 9). HA-N ${ }_{3}$ was first acidified by adding aq. HCl, so as to be totally soluble in DMSO. HA-N $(18 \mathrm{mg}, 3.5 \mu \mathrm{mol})$, copper sulfate $(9 \mathrm{mg}, 36 \mu \mathrm{mol})$, sodium ascorbate $(18 \mathrm{mg}, 90 \mu \mathrm{mol})$ and TBTA $(22 \mathrm{mg}, 41 \mu \mathrm{mol})$ were added to a solution of ELP-Alk $(60 \mathrm{mg}, 3.5 \mu \mathrm{mol})$ in anhydrous DMSO $(6 \mathrm{~mL})$ under argon atmosphere. The mixture was stirred at $40{ }^{\circ} \mathrm{C}$ for 4 days, after which the reaction was diluted with cold water $(20 \mathrm{~mL})$ and cooled in a refrigerator at $4{ }^{\circ} \mathrm{C}$ for $20 \mathrm{~min}$. TBTA was precipitated and removed by centrifugation. Cuprisorb $(180 \mathrm{mg})$ was added to the resulted solution and it was then incubated at r.t with shaking, for overnight to remove the copper. The solution containing cuprisorb was centrifuged and the supernatant was purified by dialysis (dialysis bag MWCO $15 \mathrm{kDa}$ ) against 
pure water for 5 days (changing water 3 times per day), followed by lyophilization to obtain the crude product $(53 \mathrm{mg})$. The crude product was redissolved in deionized water $(5.3 \mathrm{~mL})$ and the solution was then heated to $40{ }^{\circ} \mathrm{C}$ and kept for $1 \mathrm{~h}$. The insoluble unreacted ELPs were centrifuged at $13,000 \mathrm{~g}$ for $20 \mathrm{~min}$ at $40{ }^{\circ} \mathrm{C}$. The supernatant was lyophilized to give the final product as a white powder (42 mg, $54 \%$ yield). ${ }^{1} \mathrm{H}$ NMR (400 MHz, $\left.\mathrm{D}_{2} \mathrm{O}\right): \delta 7.75$ (s, triazole $\mathrm{H}$ ), 7.60-7.09 (br, indole $H$ Trp), 4.62-4.37 (br, $\mathrm{CH}_{\alpha}$ Met, Val, Pro, GlcUA H-1, GlcNAc H-1), 4.17 (d, $\mathrm{CH}_{\alpha}$ Val $_{\text {Xaa }}$ ), 4.04-3.66 (br, $\mathrm{CH}_{2 \alpha}$ Gly, $\mathrm{CH}_{2 \delta}$ Pro, $\mathrm{CH}_{2}{ }^{\prime}$ Pro, GlcUA H-4, GlcNAc H-2, H-3, H-5, H-6), 3.65-3.42 (GlcUA H-3, H-5), 3.41-3.30 (t, GlcUA H-2), 2.69-2.48 (br m, $\mathrm{CH}_{2 \gamma}$ Met), 2.41-2.25 (m, $\mathrm{CH}_{2 \beta}$ Pro), $2.20-1.89$ (m, $\mathrm{CH}_{2 \beta}$ Met, $\mathrm{CH}_{2}{ }^{\prime} \beta$ Pro $\mathrm{CH}_{2 \gamma}$ Pro, $\mathrm{CH}_{\beta}$ Val, $\mathrm{CH}_{3 \varepsilon}$ Met, $\mathrm{CH}_{3}$ GlcNAc), $1.06-0.88$ (m, $\mathrm{CH}_{3 \gamma}$ Val). FT-IR (ATR): 3298, 2964, 1631, 1528, 1440, 1232, $1153,1044,541 \mathrm{~cm}^{-1}$.

\section{Characterization Methods}

\section{Nuclear Magnetic Resonance Spectrometry Analysis (NMR)}

NMR spectra were acquired in $\mathrm{D}_{2} \mathrm{O}$ or $\mathrm{CDCl}_{3}$ at $298 \mathrm{~K}$ on a Bruker Avance I NMR spectrometer operating at $400.2 \mathrm{MHz}$ and equipped with a Bruker multinuclear z-gradient direct probe head capable of producing gradients in the $\mathrm{z}$ direction with $53.5 \mathrm{G}_{\mathrm{cm}} \mathrm{cm}^{-1}$ strength. The relaxation time was fixed to 3 seconds for homonuclear correlation spectroscopy (COSY) measurements.

\section{Mass Spectrometry Analysis (MS)}

Mass spectrometry analyses were performed on a MALDI TOF/TOF (Ultraflex III, Bruker Daltonics, Bremen, Germany) equipped with a SmartBeam laser (Nd:YAG, $355 \mathrm{~nm}$ ). Solutions of ELPs were prepared as follows: lyophilized ELPs were resuspended in water/acetonitrile (1/1, $\mathrm{v} / \mathrm{v}$ ) to obtain a final concentration lower than $100 \mu \mathrm{M}$. Samples were then mixed with the matrix solution of sinapinic acid prepared at the concentration of $10 \mathrm{mg} / \mathrm{mL}$ in water/acetonitrile $(1 / 1$, 
$\mathrm{v} / \mathrm{v})$. All MALDI-MS measurements were acquired in the linear positive mode and a mixture of standard proteins was used for external calibration in the suitable mass range $(10-20 \mathrm{kDa})$.

\section{Size Exclusion Chromatography (SEC)}

SEC analysis was performed on a SEC-MALS system with refractive index and laser scattering detectors (WYATT Technology Optilab rEX and HELEOS-II) using an aqueous buffer (0.1 M $\mathrm{NaNO}_{3}, 0.01 \mathrm{M} \mathrm{Na}_{2} \mathrm{HPO}_{4}, 0.02 \mathrm{M} \mathrm{NaN}_{3}$ ) with a flow rate of $0.6 \mathrm{~mL} / \mathrm{min}$ at $22{ }^{\circ} \mathrm{C}$. The specific refractive index increment $(\mathrm{dn} / \mathrm{dc})$ of polysaccharide- $b$-ELP bioconjugates were measured by means of a differential refractometer (Wyatt Optilab rEX) operating at a wavelength of $658 \mathrm{~nm}$ at $26{ }^{\circ} \mathrm{C}$. A single concentration of each bioconjugate was used to determine the $\mathrm{dn} / \mathrm{dc}$ coefficient through the calculation module implemented in the Astra 7.1 software. The measured $\mathrm{dn} / \mathrm{dc}$ values of polysaccharide- $b$-ELP bioconjugates were applied for the calculation of weight average molecular weight $\left(\mathrm{M}_{\mathrm{w}}\right)$.

\section{Fourier Transform Infrared Spectroscopy (FT-IR)}

FT-IR spectra were recorded using a Bruker Vertex 70 spectrometer with a GladiATR diamond. Spectra were recorded directly on a powder samples at 400-4000 $\mathrm{cm}^{-1}$ (resolution of 4 wavenumber) range by using attenuated total reflection mode.

\section{Transition Temperature Measurements $\left(T_{t}\right)$}

$T_{\mathrm{t}}$ were determined by measuring the turbidity at $350 \mathrm{~nm}$ between 10 and $80{ }^{\circ} \mathrm{C}$ at a $1{ }^{\circ} \mathrm{C} / \mathrm{min}^{-1}$ scan rate at different concentrations in DI water. Data were collected on a Cary $100 \mathrm{UV}-\mathrm{Vis}$ spectrophotometer equipped with a multicell thermoelectric temperature controller from Agilent Technologies (Les Ulis, FR). The $T_{\mathrm{t}}$ is defined as the temperature corresponding to the point where the maximum standard deviation on the absorbance versus temperature plots. 


\section{Dynamic Light Scattering Measurements (DLS)}

Dynamic light scattering measurements were performed on NanoZS instrument (Malvern, U.K.) at a $90^{\circ}$ angle at a constant position in the cuvette (constant scattering volume). The derived count rate (DCR) was defined as the mean scattered intensity normalized by the attenuation factor. The DCR was plotted against temperature and the $T_{\mathrm{t}}$ is defined as the temperature corresponding to the point where the DCR starts increasing on this plot.

\section{Temperature-controlled Liquid Atomic Force Microscopy (Liquid AFM)}

Temperature-controlled liquid atomic force microscopy measurements were performed using a Dimension FastScan Bruker AFM system. The topography images of the bioconjugates were obtained in Peak Force tapping mode, using a Silicon cantilever (ScanAsyst-Fluid+, Bruker) with a typical tip radius of $5 \mathrm{~nm}$. The cantilever resonance was $150 \mathrm{kHz}$ and the spring constant was $0.7 \mathrm{~N} / \mathrm{m}$. Substrates were purchased from Agar Scientific. Samples were prepared by dropcasting a bioconjugates water solution of $50 \mu \mathrm{M}(150 \mu \mathrm{M}$ for HA-b-ELP) onto a freshly cleaved mica or HOPG surface, which was directly applied for imaging. AFM imaging process was conducted in liquid environment at specific temperature. An external heating stage (Bruker) was used to achieve the target temperature at the substrate surface.

\section{RESULTS AND DISCUSSION}

\section{Synthesis of polysaccharide- $b$-ELP block copolymers}


The synthetic strategy was based on a coupling reaction between the polysaccharide and ELP blocks via copper(I)-catalyzed azide-alkyne cycloaddition (CuAAC) which has previously been applied for biomacromolecular conjugation with high selectivity and coupling efficiency. ${ }^{87}$ For this purpose, the three selected polysaccharides and the ELP needed to be functionalized with either an azide or an alkyne group. In most cases, polysaccharides can be straightforwardly modified at their reducing end by azide-containing amines in acidic conditions with excellent functionalization degrees. Regarding the introduction of an alkyne group at the ELP chain end, an activated alkyne-functionalized NHS-ester can be exploited and subsequently substituted by the $N$-terminal primary amine of the ELP. ${ }^{84}$ Herein the different polysaccharides were modified at their reducing end with an azide group using a bifunctional $\mathrm{N}$-methoxyoxyamine linker and the ELP was modified at the $N$-terminal end with an alkyne moiety (Scheme 1), allowing the subsequent coupling of the two blocks by CuAAC as illustrated on Scheme 1C.

A
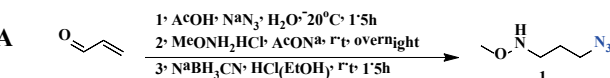

B

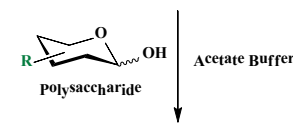

C

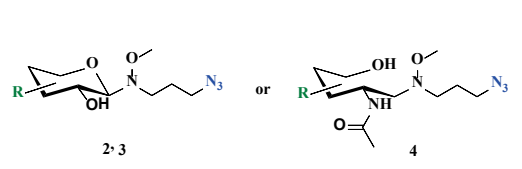

$\mathrm{CuSO}_{4}, \mathrm{Sodi}^{\mathrm{di}}$

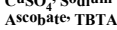

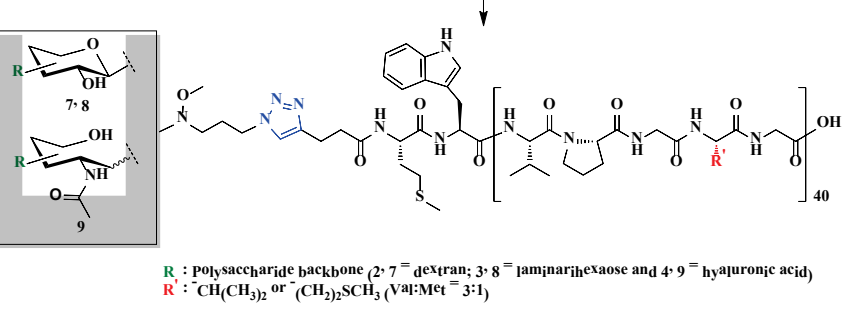

Scheme 1. Synthetic strategy of polysaccharide- $b$-elastin-like polypeptide block copolymers. (A) Synthesis of the bifunctional linker 1 and of the NHS-alkyne ester 5. (B) Reducing-end 
functionalization of polysaccharides and modification of ELP at the $N$-terminus. (C) Huisgen's cycloaddition between the azide-functionalized polysaccharides and the alkyne-functionalized ELP.

\section{Reducing-end functionalization of polysaccharides}

Primary amines have been extensively used for the functionalization of polysaccharides by reductive amination to form an open-chain monosaccharide at its reducing end. ${ }^{11,12}$ Recently the use of functional oxyamine linkers for conjugation to glycans has been demonstrated with highly efficient coupling. ${ }^{82,83}$ In comparison to the conventional reductive amination of glycans with primary amines, the use of oxyamine linkers in acetate buffer without any reducing agent was able to produce the native closed conformation of the reducing sugar, which is essential for the recognition of some saccharides to the relevant receptors. In order to explore more on this methodology for the functionalization of polysaccharides, we first prepared the azidefunctionalized oxyamine linker 1 via a three-step one-pot strategy (Scheme 1A) and characterized it by 1D and 2D NMR (Figure S1). ${ }^{82}$ This azide-linker contains an $N$ methoxyamine functional group for conjugation to the reducing end of the polysaccharides and a chain end azide group for subsequent conjugation to the ELP. ${ }^{82,83}$ The modification reactions of Dex and Lam by the oxyamine linker were carried out in acetate buffer at $40{ }^{\circ} \mathrm{C}$ at $\mathrm{pH} 4.6$ (Scheme 1B). The ${ }^{1} \mathrm{H}, \mathrm{HSQC}$ and COSY NMR spectra in $\mathrm{D}_{2} \mathrm{O}$ of modified polysaccharides were recorded and all peaks were assigned (see Figures S2, S3). Full conversion of Dex and Lam were confirmed by comparing the integral of the peak at $1.84 \mathrm{ppm}$ corresponding to the resonance of the $\beta$-methylene of oxyamine linker with the integral of the peak at $4.1 \mathrm{ppm}$ for Dex and $4.2 \mathrm{ppm}$ for Lam (anomeric proton of the reducing sugar). The two protons of $\alpha$-methylene in oxyamine linker have different resonance frequencies $(2.89 \mathrm{ppm}$ and $3.08 \mathrm{ppm})$ illustrating a 
stereochemical non-equivalence of the two protons, which indicated that the reducing sugar retained its closed conformation with a $\beta$-anomeric configuration due to the stereochemical effect of the methoxy group ${ }^{82}$, and the proton coupling constant of a $\beta$-linked sugar $(J=8.9 \mathrm{~Hz})$.

Applying the same strategy on the modification of HA by the oxyamine linker, either at $\mathrm{pH} 4.6$ or 5.5 of acetate buffer gave a conversion below $50 \%$. This may due to the high negative charge density of HA. Thus conventional reductive amination in a buffer at $\mathrm{pH} 5.5$, which has also been previously reported for the modification of $\mathrm{HA},{ }^{11}$ was applied to couple the reducing end of HA with the oxyamine linker, using sodium cyanoborohydride $\left(\mathrm{NaBH}_{3} \mathrm{CN}\right)$ as a reducing agent (Figure S4). Also, the integration of the NMR spectra of the starting HA and the azidofunctionalized HA showed the degree of functionalization (Figure S5). As a result of the reduction, the protons of the $\alpha$-methylene in the oxyamine linker have stereochemical equivalence (2.88 ppm), revealing an open chain reducing end of HA (Figure S5). Successful azide-functionalization of the three polysaccharides was also assessed by tracking the appearance of azide vibration signal at $2100 \mathrm{~cm}^{-1}$ in FTIR spectra (Figure S6, S7, S8).

\section{Alkyne functionalization at the N-terminal end of ELP}

The ELP used in this work was prepared by recombinant DNA and protein engineering techniques in Escherichia coli as described previously. ${ }^{60}$ This ELP contains in total 40 pentapeptide repeats with the protein sequence $\mathrm{MW}\left[(\mathrm{VPGVG})(\mathrm{VPGMG})(\mathrm{VPGVG})_{2}\right]_{10}$, corresponding to a molecular weight of 17,035 Da. The ELP-polysaccharide complex reported, uses lysine-containing ELPs and charged polysaccharides as polyelectrolytes to form the complex. ${ }^{78}$ In our strategy, we covalently conjugate the polysaccharide to the ELP to form a block copolymer, the ELP, having methionine residues, can be further functionalized to provide diverse possibilities of crosslinking or side-chain modifications. ${ }^{60-62}$ The MS and NMR spectra 
characterization of this "starting" ELP are provided in Figure S9 and S10. In order to introduce an alkyne group on the ELP, the activated NHS-alkyne ester $\mathbf{5}$ was synthesized by a coupling reaction between $N$-hydroxysuccinimide and 4-pentynoic acid (Scheme 1A). The reaction of the primary amine of ELP with the NHS-alkyne ester $\mathbf{5}$ was thereafter verified by ${ }^{1} \mathrm{H}$ NMR and MALDI-Tof mass spectrometry (Figure S9, S12). Even though the terminal alkyne moiety was not detected by ${ }^{1} \mathrm{H}$ NMR spectroscopy of the purified chain end-functionalized ELP, the appearance of peaks for two methylene groups of the alkyne linker at $2.3 \mathrm{ppm}$ was an indication of successful modification (Figure S12). Full alkyne functionalization of ELP was also confirmed by the MS shift to 17,119 Da after NHS-coupling chemistry (Figure S9).

\section{Synthesis of polysaccharide-b-ELP copolymers}

The emergence of "click chemistry" has revolutionized bioconjugate chemistry by affording excellent selectivity and using soft reaction conditions amenable to both synthetic polymers and fragile biomacromolecules, such as proteins or DNAs ${ }^{88}$ A widely used "click reaction" is the $\mathrm{Cu}(\mathrm{I})$-catalyzed azide-alkyne cycloaddition or Huisgen's cycloaddition ${ }^{87}$ Herein, conjugations of ELP and polysaccharides were carried out via Huisgen's cycloaddition in DMSO as common solvent for the ELP and polysaccharides (Scheme 1C). TBTA, a powerful stabilizing ligand for copper(I), was used in the conjugation of Dex and HA as they have a much higher molecular weight than Lam. The mole ratio of polysaccharides to ELP, which are 1.5:1, 5:1 and 1:1, for Dex, Lam and HA, respectively. The excess polysaccharides were removed by extensive dialysis against water and the unreacted ELP was removed by inverse transition cycling. The success of the click reaction was subsequently monitored by SEC, as well as by ${ }^{1} \mathrm{H}$, HSQC and COSY NMR and FTIR spectroscopy. 


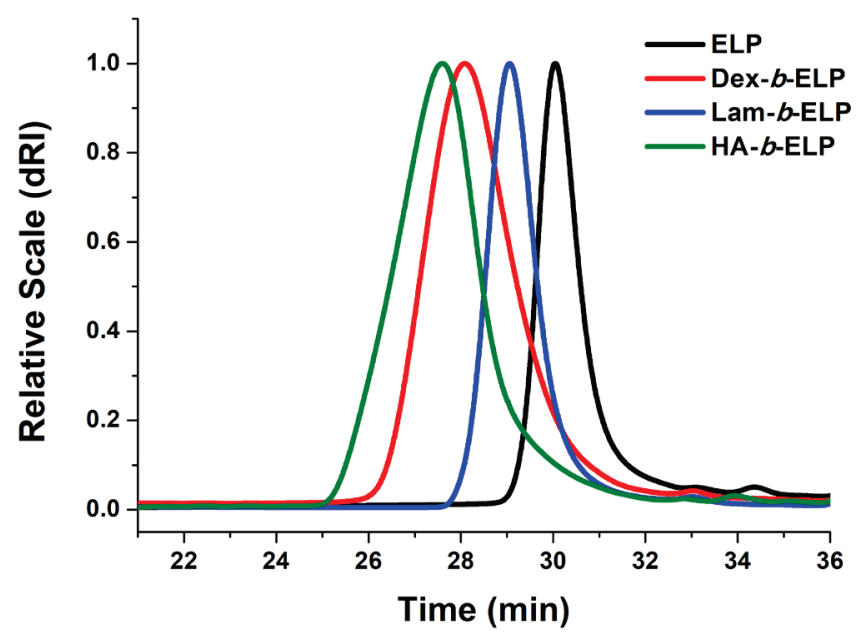

Figure 1. SEC traces of ELP and polysaccharide- $b$-ELP bioconjugates in aqueous buffer $(0.1 \mathrm{M}$

$$
\mathrm{NaNO}_{3}, 0.01 \mathrm{M} \mathrm{Na}_{2} \mathrm{HPO}_{4}, 0.02 \mathrm{M} \mathrm{NaN}_{3} \text { ) using a RI detector. }
$$

The conjugation of polysaccharides to the ELP coincided with a clear increase in the molecular weight of the different block copolymers as observed in Figure 1 and S13. SEC also highlights the low dispersity of the resulting block copolymers (Table 1). All the peaks in ${ }^{1} \mathrm{H}$ NMR spectra were assigned with the help of corresponding HSQC and COSY NMR, indicating both polysaccharide block and ELP block (see Figure S14, S15, and S16). All NMR spectra displayed the characteristic anomeric peaks of polysaccharides at around $5.0 \mathrm{ppm}$ and the triazole proton peak was found at $7.8 \mathrm{ppm}$ (Figure 2) confirming the desired structures of the block copolymers. FTIR spectra of the bioconjugates, after the click reaction, were also compared with the ones of alkyne-functionalized ELP and corresponding azide-functionalized polysaccharides (Figure S6, $\mathrm{S} 7$ and S8). The complete disappearance of the azide band at $2100 \mathrm{~cm}^{-1}$ in the bioconjugates proved the success of the "click reaction" bioconjugation. 


\begin{tabular}{ccccc}
\hline Bioconjugates & $\mathrm{M}_{\mathrm{w}}{ }^{a}(\mathrm{kDa})$ & $\begin{array}{c}\text { Polysaccharide } \\
\text { mass fraction }\end{array}$ & $\mathrm{PDI}^{a}$ & $T_{\mathrm{t}}$ in water \\
Dex- $b$-ELP & 24.9 & $32 \%$ & 1.01 & $39{ }^{\circ} \mathrm{C}$ \\
Lam- $b$-ELP & 18.2 & $5 \%$ & 1.03 & $36{ }^{\circ} \mathrm{C}$ \\
HA- $b$-ELP & 24.3 & $30 \%$ & 1.02 & $48{ }^{\circ} \mathrm{C}$ \\
\hline
\end{tabular}

Table 1. Characteristics of the polysaccharide- $b$-ELP bioconjugates synthesized. ${ }^{a}$ Weight average molecular weight $\left(\mathrm{M}_{\mathrm{w}}\right)$ and polydispersity index (PDI) were determined by SEC in aqueous buffer. ${ }^{b} T_{\mathrm{t}}$ was measured by turbidity on UV-Vis.

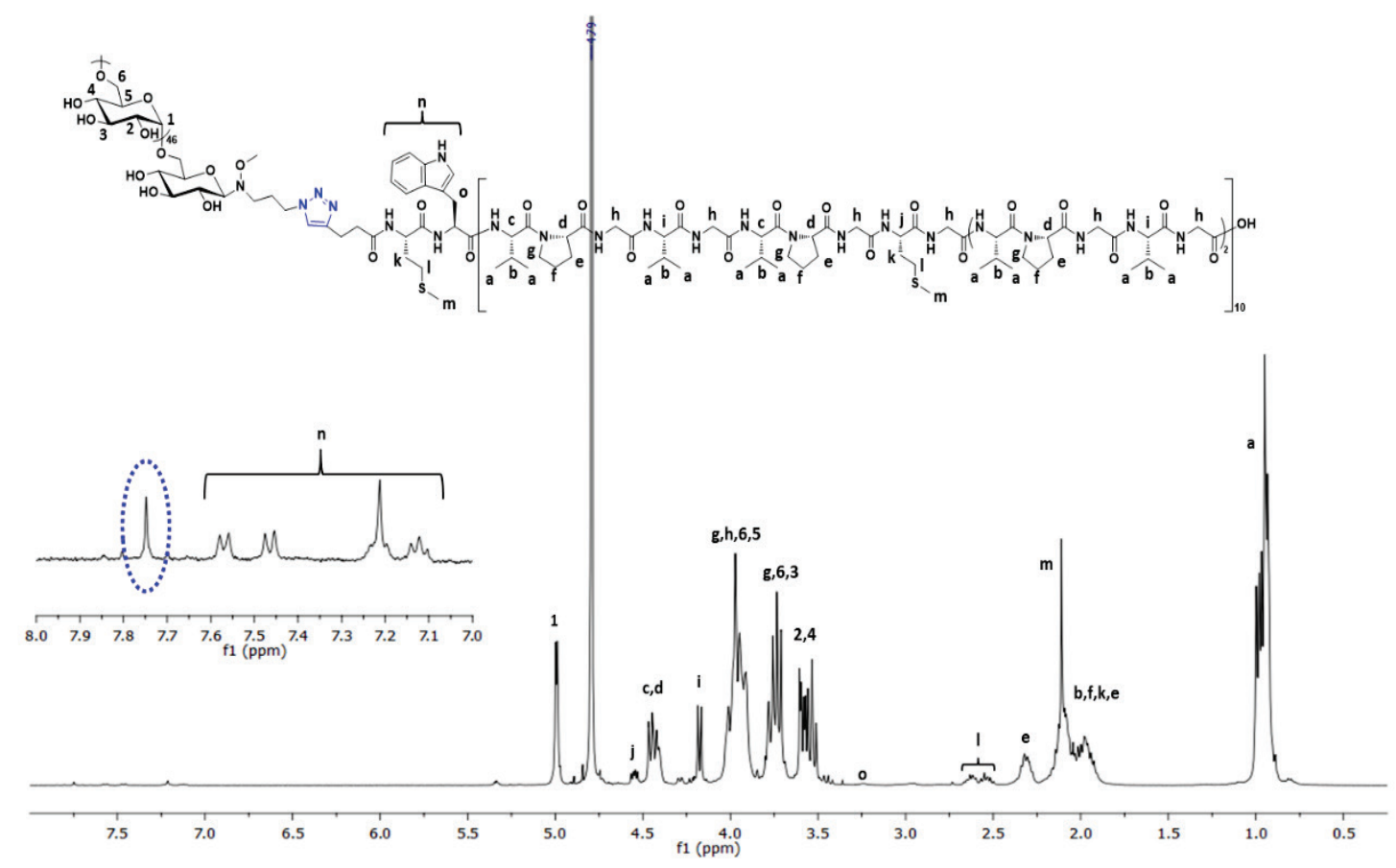




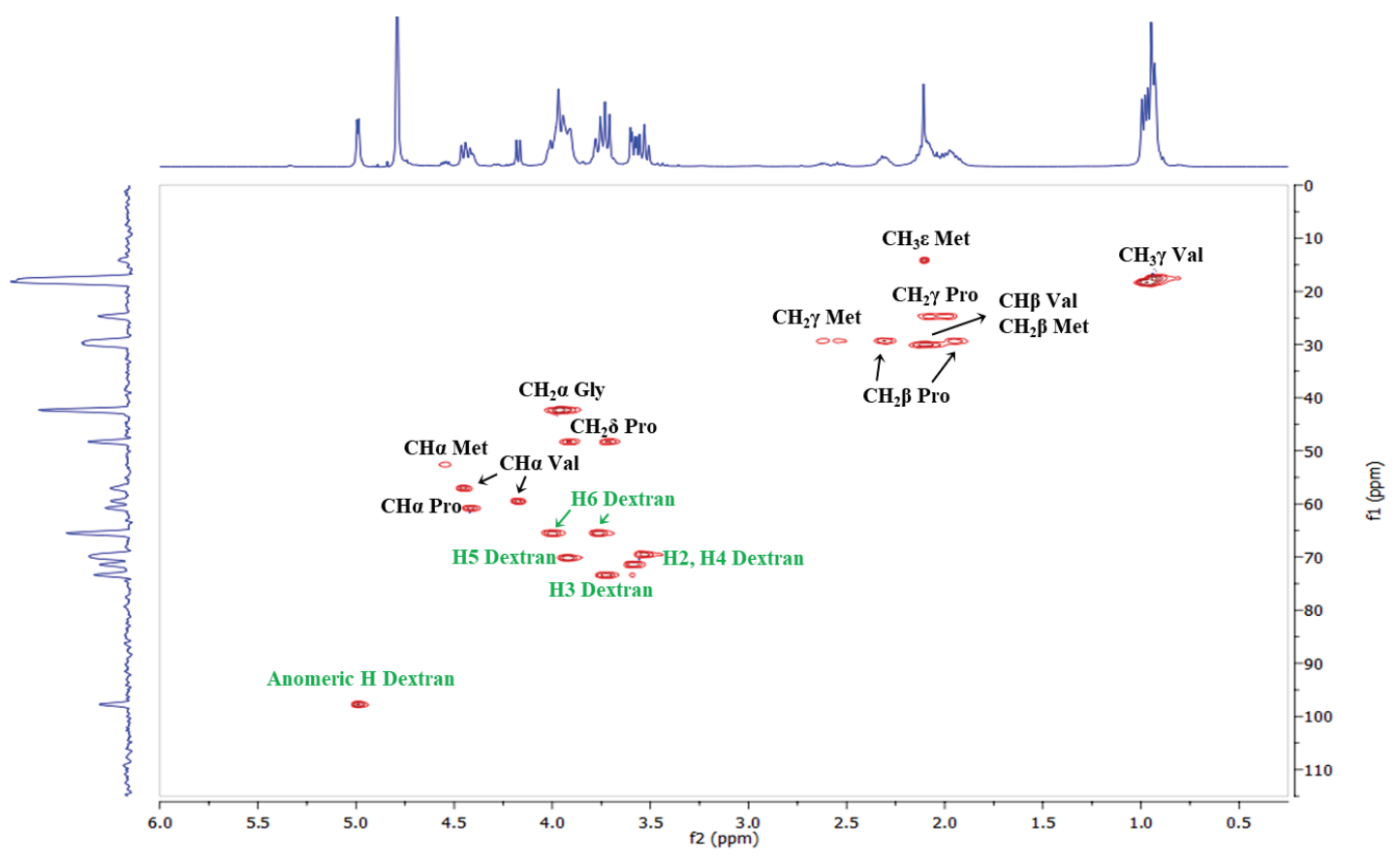

Figure 2. ${ }^{1} \mathrm{H}$ and HSQC NMR Spectra of Dex- $b$-ELP in $\mathrm{D}_{2} \mathrm{O}$ at $25{ }^{\circ} \mathrm{C}$.

\section{Temperature-triggered self-assembly of polysaccharide-b-ELP copolymers}

\section{Thermo-responsive properties}

The thermo-responsive properties of the different polysaccharide- $b$-ELP block copolymers were first studied by measuring the $T_{\mathrm{t}}$ values by turbidity measurement at $350 \mathrm{~nm}$. In contrast with $T_{\mathrm{t}}$ of ELP $\left(32{ }^{\circ} \mathrm{C}\right)$ at same concentration (Figure $\left.3 \mathrm{~A}\right), T_{\mathrm{t}}$ of the bioconjugates shifted to higher temperature depending on the hydrophilicity of polysaccharides $\left(36{ }^{\circ} \mathrm{C}, 39{ }^{\circ} \mathrm{C}\right.$ and $48{ }^{\circ} \mathrm{C}$ for Lam- $b$-ELP, Dex- $b$-ELP and HA- $b$-ELP, respectively). Consistently, the higher the hydrophilicity of the polysaccharide, the larger the $T_{\mathrm{t}}$. One can note that the slight decrease in absorption of HA- $b$-ELP at high temperature was most likely due to the formation of large aggregates, which may sediment (Figure S24). The $T_{\mathrm{t}}$ values of ELP and ELP bioconjugates were then plotted as functions of concentration (Figure 3B) and the data were fitted using the 
empirical law proposed by Chilkoti and coworkers. ${ }^{56}$ This equation gave satisfactory fits of $T_{\mathrm{t}}$, concentration and temperature, enabling accurate prediction of the $T_{\mathrm{t}}$ of ELP and its bioconjugates at specific concentrations. As the hydrophilicity of the ELP bioconjugates decreased, the slope of the fit became flatter. This result is consistent with the observations reported by Chilkoti and coworkers. ${ }^{56}$

A

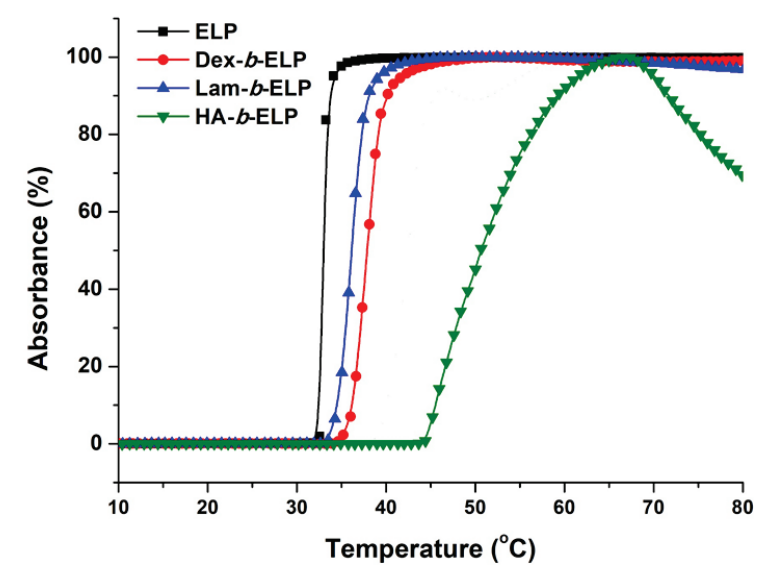

B

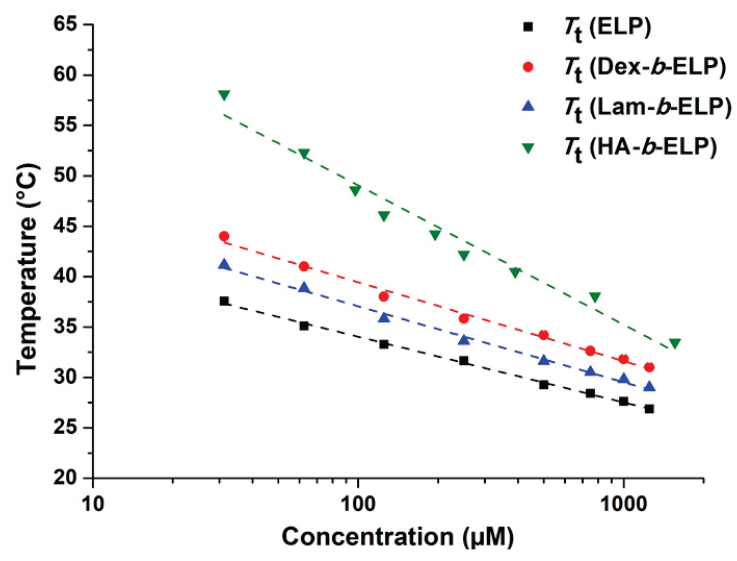

Figure 3. Turbidity study of ELP and polysaccharide- $b$-ELP bioconjugates. (A) Absorbance measured at $125 \mu \mathrm{M}$ in water as function of temperature. (B) $T_{\mathrm{t}}$ values plotted as function of concentration in water.

\section{Self-assembly of polysaccharide-b-ELP block copolymers}

In a next step, we were interested in studying the self-assembly properties of polysaccharide- $b$ ELP copolymers and their ability to form well-defined micellar structures. The behavior of Dex$b$-ELP (125 $\mu \mathrm{M}$ in water) was first analyzed by DLS. Measuring the total scattering intensity with temperature allowed the determination of $T_{\mathrm{t}}$ that was found to be around $40{ }^{\circ} \mathrm{C}$. Consistently with turbidity measurements, this value was comparable and larger than the $T_{\mathrm{t}}$ of single ELP determined at the same concentration (Figure 4A) due to the conjugation of a 
hydrophilic polysaccharide segment. Interestingly, the physical mixture of ELP and Dex did not influence the $T_{\mathrm{t}}$ of ELP (Figure 4A, S17). As observed in Figure 4A, at low temperature $\left(30^{\circ} \mathrm{C}\right)$ below $T_{\mathrm{t}}$ of Dex-b-ELP, the scattering intensity is very low, due to the presence of free copolymer chains in solution and a few aggregates (Figure S23A). The scattering intensity sharply increased at the transition temperature (around $40{ }^{\circ} \mathrm{C}$ ) and triggered the self-assembly to form structures with hydrodynamic diameter $\left(\mathrm{D}_{\mathrm{h}}\right)$ around $165 \mathrm{~nm}$. Once Dex- $b$-ELP was heated above $45^{\circ} \mathrm{C}$, the nanoparticles showed little changes in diameter with a $\mathrm{D}_{\mathrm{h}}$ of approximately 290 nm (Figure 4B, S23A), being stable until $60^{\circ} \mathrm{C}$. Repeated heating and cooling on Dex-b-ELP showed similar $\mathrm{D}_{\mathrm{h}}$ and PDI values, illustrating that this temperature-responsive behavior is fully reversible, which offers a simple method for controlling the transition of ELPs (Figure S18). Atomic force microscopy in a liquid cell was conducted to investigate the morphology of the nanostructures formed by Dex- $b$-ELP below/above $T_{\mathrm{t}}$. Consistent with the DLS results, very small objects were observed below $T_{\mathrm{t}}$ at $35^{\circ} \mathrm{C}$ (Figure 5A), and spherical-shaped particles were observed with an average diameter of approximately $280-300 \mathrm{~nm}$ above $T_{\mathrm{t}}$ at $65^{\circ} \mathrm{C}$ (Figure 5B) and with a particle thickness around 7-10 nm (Figure S25A). 
A

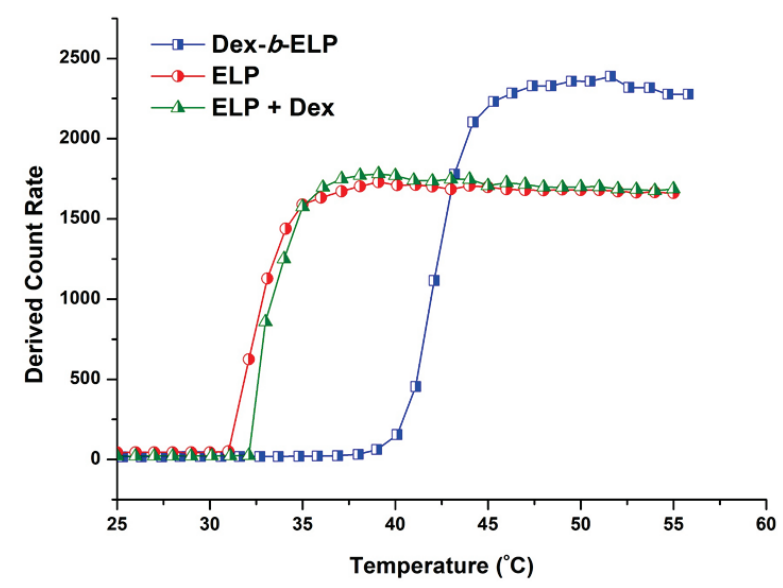

B

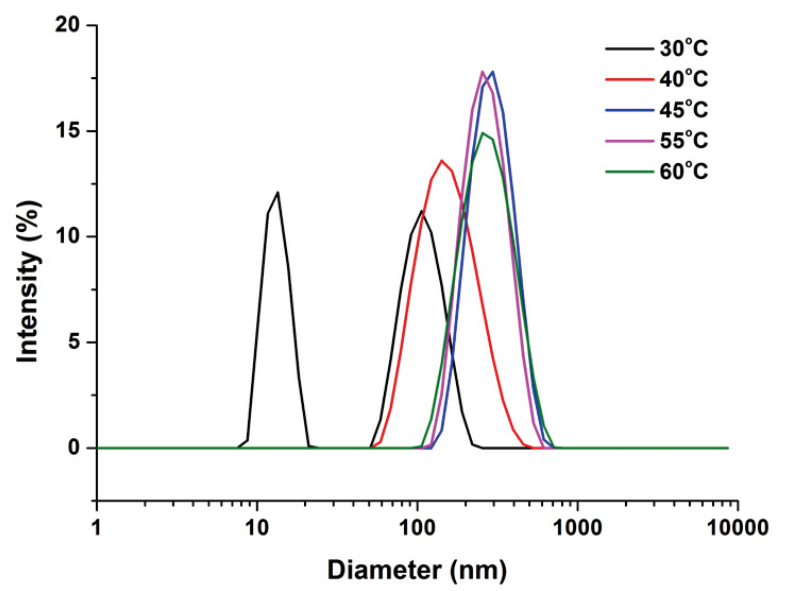

Figure 4. Dynamic light scattering analysis of the self-assembly of ELP, Dex- $b$-ELP and physical mixture of ELP and Dex at $125 \mu \mathrm{M}$ in water. (A) Scattered intensity as a function of temperature upon heating. (B) Size distribution in intensity of Dex-b-ELP at selected temperatures.

Due to the small hydrophilic fraction of Lam- $b$-ELP, the $T_{\mathrm{t}}$ of Lam- $b$-ELP was found around $33{ }^{\circ} \mathrm{C}$, which is slightly higher when compared to the $T_{\mathrm{t}}$ of ELP (Figure S19). At low temperature $\left(30^{\circ} \mathrm{C}\right)$, below $T_{\mathrm{t}}$ of Lam- $b$-ELP, small objects and a few aggregates were observed with very low scattering intensity (Figure S23B). The scattering intensity sharply increased at transition temperature (around $33^{\circ} \mathrm{C}$ ) and triggered the self-assembly to form structures with $\mathrm{D}_{\mathrm{h}}$ around $210 \mathrm{~nm}$ (Figure S23B). Unlike Dex- $b$-ELP, a peak located at $36-38{ }^{\circ} \mathrm{C}$ was most likely due to the formation of unstable big particles, which precipitated thus decreasing the concentration in the detected area. Repeated heating and cooling of Lam- $b$-ELP from $25{ }^{\circ} \mathrm{C}$ to $36{ }^{\circ} \mathrm{C}$ on DLS also illustrated this unstable behavior (Figure S20). Nevertheless the temperatureresponsive behavior of Lam- $b$-ELP is fully reversible. When temperature was heated above $45^{\circ} \mathrm{C}$, the nanoparticles showed little changes in scattering intensity and displayed diameter with a $\mathrm{D}_{\mathrm{h}}$ of approximately 400-500 nm (Figure S20). Liquid AFM even recorded larger diameters 
(500-900) for the aggregates of Lam- $b$-ELP above the $T_{\mathrm{t}}$ (Figure 5D) and particle thickness was found around 3-5 nm (Figure S25B).

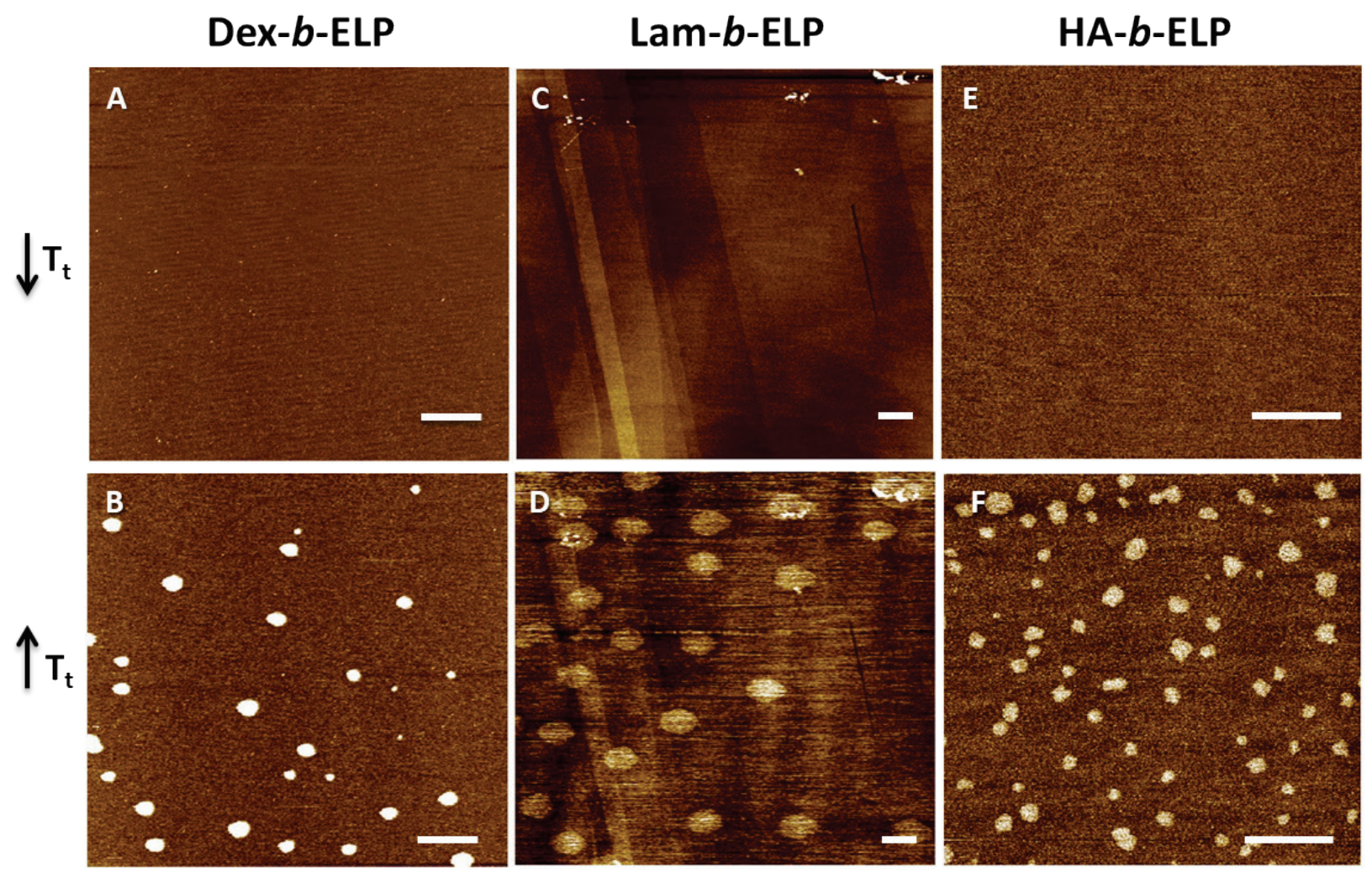

Figure 5. Liquid AFM images of Dex- $b$-ELP (50 $\mu \mathrm{M}$ in water) on mica substrate at: (A) $35{ }^{\circ} \mathrm{C}$ and (B) $65{ }^{\circ} \mathrm{C}$. Lam- $b$-ELP $\left(50 \mu \mathrm{M}\right.$ in water) on HOPG substrate at: (C) $30{ }^{\circ} \mathrm{C}$ and (D) $55{ }^{\circ} \mathrm{C}$. HA- $b$-ELP $\left(150 \mu \mathrm{M}\right.$ in water) on mica substrate at: (E) $25{ }^{\circ} \mathrm{C}$ and (F) $52{ }^{\circ} \mathrm{C}$. The scale bar indicates $1 \mu \mathrm{m}$.

Similar to the UV-vis measurements, the $T_{\mathrm{t}}$ of HA- $b$-ELP on DLS heating ramp was found around $45^{\circ} \mathrm{C}$. At low temperature $\left(35^{\circ} \mathrm{C}\right)$ below $T_{\mathrm{t}}$ of HA- $b$-ELP, small objects were observed with very low scattering intensity (Figure S23C). The scattering intensity sharply increased at transition temperature and triggered the self-assembly to form structures with $\mathrm{D}_{\mathrm{h}}$ around $300 \mathrm{~nm}$ at $48-50{ }^{\circ} \mathrm{C}$ (Figure S21, S23C). Once HA-b-ELP was heated above $55^{\circ} \mathrm{C}$, the diameter of 
nanoparticles became unstable and separated into two size distributions, which was also confirmed by liquid AFM (Figure S24). Nanoparticles with an average diameter of approximately 220-280 nm and a particle thickness of 0.5-1.5 nm were observed by liquid AFM at $50{ }^{\circ} \mathrm{C}$ (Figure $5 \mathrm{~F}, \mathrm{~S} 25 \mathrm{C}$ ) at the same concentration. The stability of the HA- $b$-ELP assemblies at $48{ }^{\circ} \mathrm{C}$ was investigated by repeated heating and cooling on DLS. This temperature-responsive system was again found fully reversible and HA- $b$-ELP nanoparticles proved relatively stable at $48{ }^{\circ} \mathrm{C}$ for 20 minutes with an average diameter around $280 \mathrm{~nm}$ on every single heating time (Figure S22).

We hypothesized that the polysaccharide- $b$-ELP block copolymers may behave similarly to the ELP diblock copolymer, in which self-assembly undergoes a chain aggregation followed by ELP core dehydration ${ }^{71}$. However, in the presence of hydrophilic polysaccharides, molar mass and charge density of the polysaccharide, and interactions between the polysaccharide and ELP, would contribute to the "unstable" chain aggregation process. Self-assembly characteristics of polysaccharide- $b$-ELP block copolymers were summarized in Table 2.

\begin{tabular}{|c|c|c|c|c|c|c|c|}
\hline \multirow{2}{*}{ Bioconjugates } & \multirow{2}{*}{ Conc. $(\mu \mathrm{M})$} & \multirow{2}{*}{$T_{\mathrm{t}} \mathrm{DLS}$} & \multicolumn{2}{|c|}{ DLS } & \multirow{2}{*}{ Conc. $(\mu \mathrm{M})$} & \multicolumn{2}{|c|}{ AFM } \\
\hline & & & $\mathrm{T}\left({ }^{\circ} \mathrm{C}\right)$ & $\operatorname{Size}(\mathrm{nm})$ & & $\mathrm{T}\left({ }^{\circ} \mathrm{C}\right)$ & $\operatorname{Size}(\mathrm{nm})$ \\
\hline \multirow{2}{*}{ Dex- $b$-ELP } & \multirow{2}{*}{125} & \multirow{2}{*}{$39^{\circ} \mathrm{C}$} & \multirow[t]{2}{*}{45} & \multirow[t]{2}{*}{300} & \multirow{2}{*}{50} & 35 & I \\
\hline & & & & & & 65 & $190-340$ \\
\hline \multirow{2}{*}{ Lam- $b$-ELP } & \multirow{2}{*}{125} & \multirow{2}{*}{$33{ }^{\circ} \mathrm{C}$} & 33 & 210 & \multirow{2}{*}{50} & 30 & / \\
\hline & & & 45 & 520 & & 55 & $500-900$ \\
\hline \multirow{2}{*}{ HA- $b$-ELP } & \multirow[t]{2}{*}{150} & \multirow[t]{2}{*}{$46^{\circ} \mathrm{C}$} & \multirow[t]{2}{*}{48} & \multirow{2}{*}{300} & \multirow[t]{2}{*}{150} & 25 & I \\
\hline & & & & & & 52 & $200-300$ \\
\hline
\end{tabular}

Table 2. Self-assembly characteristics of polysaccharide- $b$-ELP block copolymers. 


\section{CONCLUSION}

We herein presented a modular approach to combine inert (Dex) and bioactive (Lam and HA) polysaccharides with a stimuli-responsive elastin-like polypeptide (ELP) into well-defined block copolymers. Polysaccharides were successfully functionalized with an azide moiety at the reducing end using a bifunctional $N$-methoxyoxyamine linker for further conjugation to the ELP. NHS-ester coupling chemistry was utilized to modify the $N$-terminal primary amine of ELP with an alkyne group. Thereafter, smart polysaccharide- $b$-ELP block copolymers were produced by $\mathrm{CuAAC}$, and their thermal responsiveness was studied by turbidity measurements. Increasing temperature above the phase transition of ELP bioconjugates resulted in the formation of amphiphiles, which self-assembled into well-defined and stable nano-objects. Stable objects with a size of a few hundreds nanometers have been evidenced, especially when the hydrophilic polysaccharide segment was large enough. In addition, the self-assembly process was fully reversible by controlling the temperature. This is the first study that proposes the conjugation of bioactive polysaccharides with stimuli-responsive ELPs for the preparation of thermo-sensitive bioactive self-assemblies, providing insight into novel pathways for designing "smart" and biologically-active nanocarriers for applications in biomaterial, drug delivery and receptor recognition.

\section{ASSOCIATED CONTENT}

\section{Supporting Information}

Synthesis route of HA-azide; Characterization (NMR, FTIR) of azide-functionalized Dex, Lam, HA and alkyne-functionalized ELP. MALDI of ELP and ELP-Alk; Characterization (SEC, NMR, 
FTIR) of Dex- $b$-ELP, Lam- $b$-ELP and HA- $b$-ELP. DLS heating ramp data of ELP bioconjugates; Liquid AFM images of HA- $b$-ELP at $55^{\circ} \mathrm{C}$.

\section{AUTHOR INFORMATION}

Corresponding Authors

*E-mail: garanger@enscbp.fr

*E-mail: lecommandoux@enscbp.fr

ORCID

Elisabeth Garanger: 0000-0001-9130-8286

Sébastien Lecommandoux: 0000-0003-0465-8603

Notes

The authors declare no competing financial interest.

\section{ACKNOWLEDGEMENTS}

We acknowledge the China Scholarship Council and Université de Bordeaux (UB-CSC 2015) for the financial support. Campus-B project, CNRS, Univ. Bordeaux, Bordeaux INP and the Région Nouvelle Aquitaine are also acknowledged. This work was also supported by the French National Research Agency (ANR-15-CE07-0002) and the Cancéropole Grand Sud-Ouest (Emergence 2018-E18). The authors thank Guillaume Goudounet, Delphine Portes and Yunjie Xia for the bioproduction of ELPs, Amelie Vax and Anne-Laure Wirotius for the help with SEC and NMR measurements and analysis. 


\section{REFERENCES}

[1] Peyret, A.; Zhao, H.; Lecommandoux, S. Preparation and Properties of Asymmetric Synthetic Membranes Based on Lipid and Polymer Self-Assembly. Langmuir 2018, 34 (11), $3376-3385$.

[2] Trantidou, T.; Friddin, M.; Elani, Y.; Brooks, NJ.; Law, RV.; Seddon, JM.; Ces, O. Engineering Compartmentalized Biomimetic Micro- and Nanocontainers. ACS Nano. 2017, $11(7), 6549-6565$.

[3] Huang, G.; Li, F.; Zhao, Xin.; Ma, Y.; Y Li.; Lin, M.; Jin, G.; Lu, TJ.; Genin, GM.; Xu, F. Functional and Biomimetic Materials for Engineering of the Three-Dimensional Cell Microenvironment. Chem. Rev. 2017, 117 (20), 12764-12850.

[4] Kataoka, K.; Harada, A.; Nagasaki, Y. Block Copolymer Micelles for Drug Delivery: Design, Characterization and Biological Significance. Adv. Drug Delivery Rev. 2001, 47(1), $113-131$.

[5] Eetezadi, S.; Ekdawi, SN.; Allen, C. The Challenges Facing Block Copolymer Micelles for Cancer Therapy: In Vivo Barriers and Clinical Translation. Adv. Drug Delivery Rev. 2015, $91,7-22$.

[6] Kutikov, AB.; Song, J. Biodegradable PEG-Based Amphiphilic Block Copolymers for Tissue Engineering Applications. ACS Biomater. Sci. Eng. 2015, 1 (7), 463-480.

[7] Hou, Y.; Lu, H. Protein PEPylation: A New Paradigm of Protein-Polymer Conjugation. Bioconjug. Chem. 2019, 30 (6), 1604-1616. 
[8] Le Fer, G.; Wirotius, AL.; Brûlet, A.; Garanger, E.; Lecommandoux, S. Self-Assembly of Stimuli-Responsive Biohybrid Synthetic- $b$-Recombinant Block Copolypeptides. Biomacromolecules 2019, 20 (1), 254-272.

[9] Sanson, C.; Schatz, C.; Le Meins, JF.; Brûlet, A.; Soum, A.; Lecommandoux, S. Biocompatible and Biodegradable Poly(trimethylene carbonate)- $b$-Poly(l-glutamic acid) Polymersomes: Size Control and Stability. Langmuir 2010, 26 (4), 2751-2760.

[10] Zhang, A.; Zhang, Z.; Shi, F.; Xiao, C.; Ding, J.; Zhuang, X.; He, C.; Chen, L.; Chen, X. Redox-Sensitive Shell-Crosslinked Polypeptide-block-Polysaccharide Micelles for Efficient Intracellular Anticancer Drug Delivery. Macromol. Biosci. 2013, 13 (9), 1249-1258.

[11] UpadHAy, KK.; Le Meins, JF.; Misra, A.; Voisin, P.; Bouchaud, V.; Ibarboure, E.; Schatz, C.; Lecommandoux, S. Biomimetic Doxorubicin Loaded Polymersomes from Hyaluronanblock-Poly( $\gamma$-benzyl glutamate) Copolymers. Biomacromolecules 2009, 10 (10), 2802-2808.

[12] Schatz, C.; Louguet, S.; Le Meins, JF.; Lecommandoux. S. Polysaccharide-blockPolypeptide Copolymer Vesicles: Towards Synthetic Viral Capsids. Angew. Chem., Int. Ed. 2009, 48 (14), 2572-2575.

[13] Guo, J.; Hong, H.; Chen, G.; Shi, S.; Nayak, TR.; Theuer, CP.; Barnhart, TE.; Cai, W.; Gong, S. Theranostic Unimolecular Micelles Based on Brush-Shaped Amphiphilic Block Copolymers for Tumor-Targeted Drug Delivery and Positron Emission Tomography Imaging. ACS Appl. Mater. Interfaces. 2014, 6 (24), 21769-21779. 
Author manuscript version of article $\underline{Y .}$ Xiao et al, Biomacromolecules 2020, 21 (1), 114-125

[14] Schöttner, S.; Schaffrath, HJ.; Gallei, M. Poly(2-hydroxyethyl methacrylate)-Based Amphiphilic Block Copolymers for High Water Flux Membranes and Ceramic Templates. Macromolecules 2016, 49 (19), 7286-7295.

[15] Stimulus-Responsive Degradable Polylactide-Based Block Copolymer Nanoassemblies for Controlled/Enhanced Drug Delivery. Mol. Pharm. 2017, 14 (8), 2460-2474.

[16] Tyler, B.; Gullotti, D.; Mangraviti, A.; Utsuki, T.; Brem, H. Polylactic acid (PLA) Controlled Delivery Carriers for Biomedical Applications. Adv. Drug Deliv. Rev. 2016, 107, $163-175$.

[17] Dash, TK.; Konkimalla. VB. Polymeric Modification and Its Implication in Drug Delivery: Poly- $\varepsilon$-caprolactone (PCL) as a Model Polymer. Mol. Pharm. 2012, 9 (9), 2365-2379.

[18] Bacinello, D.; Garanger, E.; Taton, D.; Tam, KC.; Lecommandoux, S. EnzymeDegradable Self-Assembled Nanostructures from Polymer-Peptide Hybrids. Biomacromolecules 2014, 15 (5), 1882-1888.

[19] Swierczewska, M.; Han, HS.; Kim, K.; Park, JH.; Lee, S. Polysaccharide-Based Nanoparticles for Theranostic Nanomedicine. Adv. Drug Delivery Rev. 2016, 99 (Pt A), 7084.

[20] Liu, Z.; Jiao, Y.; Wang, Y.; Zhou, C.; Zhang, Z. Polysaccharides-Based Nanoparticles as Drug Delivery Systems. Adv. Drug Delivery Rev. 2008, 60 (15), 1650-1662.

[21] Rosselgong, J.; Chemin, M.; Cabral Almada, C.; Hemery, G.; Guigner, J.-M.; Chollet, Gu; Labat, G.; da Silva Perez, D.; Ham-Pichavant, F.; Grau, E.; Grelier, S.; Lecommandoux, S; 
Author manuscript version of article $\underline{Y .}$ Xiao et al, Biomacromolecules 2020, 21 (1), 114-125

Cramail, H. Synthesis and Self-Assembly of Xylan-Based Amphiphiles: From Bio-Based Vesicles to Antifungal Properties. Biomacromolecules 2019, 20 (1), 118-129.

[22] Rabotyagova, OS.; Cebe, P.; Kaplan, DL. Protein-Based Block Copolymers. Biomacromolecules 2011, 12 (2), 269-289.

[23] Seidi, K.; Neubauer, HA.; Moriggl, R.; Jahanban-Esfahlan, R.; Javaheri, T. Tumor Target Amplification: Implications for Nano Drug Delivery Systems. J. Controlled Release 2018, $275,142-161$.

[24] Cai, L.; Gu, Z.; Zhong, J.; Wen, D.; Chen, G.; He, L.; Wu, J.; Gu, Z. Advances in Glycosylation-Mediated Cancer-Targeted Drug Delivery. Drug Discov. Today 2018, 23 (5), $1126-1138$.

[25] Huang, GL.; Huang, HL. Hyaluronic Acid-based Biopharmaceutical Delivery and TumorTargeted Drug Delivery System. J. Controlled Release 2018, 278, 122-126.

[26] Wang, SS.-S.; How, S-C.; Chen, Y-D.; Tsaic, Y-H.; Jan J-S. Bioactive SaccharideConjugated Polypeptide Micelles for Acid-Triggered Doxorubicin Delivery. J. Mater. Chem. $B, \mathbf{2 0 1 5}, 3,5220-5231$.

[27] Huang, J.; Bonduelle, C.; Thévenot, J.; Lecommandoux, S.; Heise, A. Biologically Active Polymersomes from Amphiphilic Glycopeptides. J. Am. Chem. Soc. 2012, 134 (1), 119-122.

[28] Garanger, E.; Lecommandoux, S. Towards Bioactive Nanovehicles Based on Protein Polymers. Angew. Chem., Int. Ed. 2012, 51 (13), 3060-3062. 
Author manuscript version of article $\underline{Y .}$ Xiao et al, Biomacromolecules 2020, 21 (1), 114-125

[29] Bonduelle, C.; Lecommandoux, S. Synthetic Glycopolypeptides as Biomimetic Analogues of Natural Glycoproteins. Biomacromolecules 2013, 14 (9), 2973-2983.

[30] Ahsan, SM.; Thomas, M.; Reddy, KK.; Sooraparaju, SG.; Asthana, A.; Bhatnagar, I. Chitosan as biomaterial in drug delivery and tissue engineering. Int. J. Biol. Macromol. 2018, $110,97-109$.

[31] VK Thakur.; MK Thakur. Recent Advances in Graft Copolymerization and Applications of Chitosan: A Review. ACS Sustainable Chem. Eng. 2014, 212, 2637-2652.

[32] Gu, D.; Huang, L.; Chen, X.; Wu, Q.; Ding, K. Structural Characterization of a Galactan From Ophiopogon Japonicus and Anti-Pancreatic Cancer Activity of Its Acetylated Derivative. Int. J. Biol. Macromol. 2018, 113, 907-915.

[33] Chiang, CS.; Lin, YJ.; Lee, R.; Lai, YH.; Cheng, HW.; Hsieh, CH.; Shyu, WC.; Chen, SY. Combination of Fucoidan-Based Magnetic Nanoparticles and Immunomodulators Enhances Tumour-Localized Immunotherapy. Nat. Nanotechnol. 2018, 13 (8), 746-754.

[34] Duan, H.; Donovan, M.; Foucher, A.; Schultze, X.; Lecommandoux, S. Multivalent and Multifunctional Polysaccharide-Based Particles for Controlled Receptor Recognition. Sci. Rep. 2018, 8 (1), 14730.

[35] Schatz, C.; Lecommandoux, S. Polysaccharide-Containing Block Copolymers: Synthesis, Properties and Applications of an Emerging Family of Glycoconjugates. Macromol. Rapid Commun. 2010, 31(19), 1664-1684. 
[36] Hu, X.; Zhang, Y.; Xie, Z.; Jing, X.; Bellotti, A.; Gu, Z. Stimuli-Responsive Polymersomes for Biomedical Applications. Biomacromolecules 2017, 18 (3), 649-673.

[37] Cobo, I.; Li, M.; Sumerlin, BS.; Perrier, S. Smart Hybrid Materials by Conjugation of Responsive Polymers to Biomacromolecules. Nat. Mater. 2015, 14 (2), 143-159.

[38] Stuart, M. A. C.; Huck, W. T.; Genzer, J.; Müller, M.; Ober, C.; Stamm, M.; Sukhorukov, G. B.; Szleifer, I.; Tsukruk, V. V.; Urban, M. Emerging Applications of Stimuli-Responsive Polymer Materials. Nat. Mater. 2010, 9 (2), 101-113.

[39] Hoffman, AS. Stimuli-Responsive Polymers: Biomedical Applications and Challenges for Clinical Translation. Adv. Drug Deliv. Rev. 2013, 65 (1), 10-16.

[40] Bajpai, A.K.; Shukla, SK.; Bhanu, S.; Kankane, S. Responsive Polymers in Controlled Drug Delivery. Prog. Polym. Sci. 2008, 33 (11), 1088-1118.

[41] Roy, D.; Cambre, JN.; Sumerlin, BS. Future Perspectives and Recent Advances in StimuliResponsive Materials. Prog. Polym. Sci. 2010, 35 (1-2), 278-301.

[42] Pang, X.; Jiang, Y.; Xiao, Q.; Leung, AW.; Hua, H.; Xu, C. pH-responsive polymer-drug conjugates: Design and progress. J. Controlled Release. 2016, 222, 116-129.

[43] Peeler, DJ.; Sellers, DL.; Pun, SH. pH-Sensitive Polymers as Dynamic Mediators of Barriers to Nucleic Acid Delivery. Bioconjugate Chem. 2019, 30 (2), 350-365.

[44] Sun, H.; Zhang, Y.; Zhong, Z. Reduction-Sensitive Polymeric Nanomedicines: An Emerging Multifunctional Platform for Targeted Cancer Therapy. Adv. Drug Deliv. Rev. 2018, 132, 16-32. 
Author manuscript version of article $\underline{Y .}$ Xiao et al, Biomacromolecules 2020, 21 (1), 114-125

[45] An, X.; Zhu, A.; Luo, H.; Ke, H.; Chen, H.; Zhao, Y. Rational Design of Multi-StimuliResponsive Nanoparticles for Precise Cancer Therapy. ACS Nano. 2016, 10 (6), 5947-5958.

[46] Anderson, C. F.; Cui, H. Protease-Sensitive Nanomaterials for Cancer Therapeutics and Imaging. Ind Eng Chem Res. 2017, 56 (20), 5761-5777.

[47] Kim, W.; Thévenot, J.; Ibarboure, E.; Lecommandoux, S.; Chaikof, E. L. Self-Assembly of Thermally Responsive Amphiphilic Diblock Copolypeptides into Spherical Micellar Nanoparticles. Angew. Chem., Int. Ed. 2010, 122 (25), 4353- 4356.

[48] Strandman, S.; Zhu, X.X. Thermo-Responsive block Copolymers with Multiple Phase Transition Temperatures in Aqueous Solutions. Prog. Polym. Sci. 2015, 42, 154-176.

[49] Beauté, L.; McClenaghan, N.; Lecommandoux, S. Photo-Triggered Polymer Nanomedicines: From Molecular Mechanisms to Therapeutic Applications. Adv. Drug Deliv. Rev. 2019, 138, 148-166.

[50] Zhao, Y. Light-Responsive Block Copolymer Micelles. Macromolecules 2012, 45 (9), $3647-3657$.

[51] Reddy, LH.; Arias, JL.; Nicolas, J.; Couvreur, P. Targeted Drug Delivery with Polymers and Magnetic Nanoparticles: Covalent and Noncovalent Approaches, Release Control, and Clinical Studies. Chem. Rev. 2012, 112 (11), 5818-5878.

[52] MacEwan, S. R.; Chilkoti, A. Applications of Elastin-like Polypeptides in Drug Delivery. J. Controlled Release 2014, 190, 314-330. 
Author manuscript version of article $\underline{Y .}$ Xiao et al, Biomacromolecules 2020, 21 (1), 114-125

[53] McDaniel, J. R.; Callahan, D. J.; Chilkoti, A. Drug Delivery to Solid Tumors by ElastinLike Polypeptides. Adv. Drug Delivery Rev. 2010, 62 (15), 1456-1467.

[54] Despanie, J.; Dhandhukia, JP.; Hamm-Alvarez, SF.; MacKay, JA. Elastin-Like Polypeptides: Therapeutic Applications for an Emerging Class of Nanomedicines. $J$. Controlled Release 2016, 240, 93-108.

[55] Halperin, A.; Kröger, M.; Winnik, FM. Poly(N-isopropylacrylamide) Phase Diagrams: Fifty Years of Research. Angew. Chem., Int. Ed. 2015, 54 (51), 15342-15367.

[56] Meyer, D. E.; Chilkoti, A. Quantification of the Effects of Chain Length and Concentration on the Thermal Behavior of Elastin-like Polypeptides. Biomacromolecules 2004, 5 (3), $846-851$.

[57] Li, N. K.; Roberts, S.; Quiroz, F. G.; Chilkoti, A.; Yingling, Y. G. Sequence Directionality Dramatically Affects LCST Behavior of Elastin-Like Polypeptides. Biomacromolecules 2018, 19 (7), 2496-2505.

[58] MacEwan, S. R.; Weitzhandler, I.; Hoffmann, I.; Genzer, J.; Gradzielski, M.; Chilkoti, A. Phase Behavior and Self-Assembly of Perfectly Sequence-Defined and Monodisperse Multiblock Copolypeptides. Biomacromolecules 2017, 18 (2), 599-609.

[59] van Eldijk, MB.; Smits, FC.; Vermue, N.; Debets, MF.; Schoffelen, S.; van Hest, JC. Synthesis and Self-Assembly of Well-Defined Elastin-Like Polypeptide-Poly (ethylene glycol) Conjugates. Biomacromolecules 2014, 15 (7), 2751-2759. 
Author manuscript version of article $\underline{Y .}$ Xiao et al, Biomacromolecules 2020, 21 (1), 114-125

[60] Petitdemange, R.; Garanger, E.; Bataille, L.; Dieryck, W.; Bathany, K.; Garbay, B.; Deming, TJ.; Lecommandoux, S. Selective Tuning of Elastin-like Polypeptide Properties via Methionine Oxidation. Biomacromolecules 2017, 18 (2), 544-550.

[61] Petitdemange, R.; Garanger, E.; Bataille, L.; Bathany, K.; Garbay, B.; Deming, TJ.; Lecommandoux, S. Tuning Thermoresponsive Properties of Cationic Elastin-like Polypeptides by Varying Counterions and Side-Chains. Bioconjugate Chem. 2017, 28 (5), $1403-1412$.

[62] Kramer, J. R.; Petitdemange, R.; Bataille, L.; Bathany, K.; Wirotius, A.-L.; Garbay, B.; Deming, T. J.; Garanger, E.; Lecommandoux, S. Quantitative Side-Chain Modifications of Methionine-Containing Elastin-Like Polypeptides as a Versatile Tool to Tune Their Properties. ACS Macro. Lett. 2015, 4 (11), 1283-1286.

[63] Malho, JM.; Brand, J.; Pecastaings, G.; Ruokolainen, J.; Gröschel, A.; Sèbe, G.; Garanger, E.; Lecommandoux, S. Multifunctional Stimuli-Responsive Cellulose Nanocrystals via Dual Surface Modification with Genetically Engineered Elastin-Like Polypeptides and Poly(acrylic acid). ACS Macro. Lett. 2018, 7 (6), 646-650.

[64] Ott, W.; Nicolaus, T.; Gaub, HE.; Nash, MA. Sequence-Independent Cloning and PostTranslational Modification of Repetitive Protein Polymers through Sortase and Sfp-Mediated Enzymatic Ligation. Biomacromolecules 2016, 17 (4), 1330-1338.

[65] Seifried, BM.; Cao, J.; Olsen, BD. Multifunctional, High Molecular Weight, PostTranslationally Modified Proteins through Oxidative Cysteine Coupling and Tyrosine Modification. Bioconjugate Chem. 2018, 29 (6), 1876-1884. 
Author manuscript version of article $\underline{Y .}$ Xiao et al, Biomacromolecules 2020, 21 (1), 114-125

[66] Zhu, D.; Wang, H.; Trinh, P.; Heilshorn, SC. Yang F. Elastin-like Protein-Hyaluronic Acid (ELP-HA) Hydrogels with Decoupled Mechanical and Biochemical Cues for Cartilage Regeneration. Biomaterials 2017, 127, 132-140.

[67] Dreher, M. R.; Raucher, D.; Balu, N.; Colvin, O. M.; Ludeman, S. M.; Chilkoti, A. Evaluation of an Elastin-Like Polypeptide-Doxorubicin Conjugate for Cancer Therapy. $J$. Controlled Release 2003, 91 (1-2), 31-43.

[68] Wang, Z.; He, Q.; Zhao, W.; Luo, J.; Gao, W. Tumor-homing, pH- and UltrasoundResponsive Polypeptide-Doxorubicin Nanoconjugates Overcome Doxorubicin Resistance in Cancer Therapy. J. Controlled Release 2017, 264, 66-75.

[69] Dreher, M. R.; Simnick, A. J.; Fischer, K.; Smith, R. J.; Patel, A.; Schmidt, M.; Chilkoti, A. Temperature Triggered Self-Assembly of Polypeptides into Multivalent Spherical Micelles. J. Am. Chem. Soc. 2008, 130 (2), 687-694.

[70] Hassouneh, W.; Zhulina, E. B.; Chilkoti, A.; Rubinstein, M. Elastin-Like Polypeptide Diblock Copolymers Self-Assemble into Weak Micelles. Macromolecules 2015, 48 (12), $4183-4195$.

[71] Garanger, E.; MacEwan, S. R.; Sandre, O.; Brûlet, A.; Bataille, L.; Chilkoti, A.; Lecommandoux, S. Structural Evolution of a Stimulus-Responsive Diblock Polypeptide Micelle by Temperature Tunable Compaction of its Core. Macromolecules 2015, 48 (18), $6617-6627$.

[72] Hassouneh W1, Fischer K, MacEwan SR, Branscheid R, Fu CL, Liu R, Schmidt M, Chilkoti A. Unexpected Multivalent Display of Proteins by Temperature Triggered Self- 
Author manuscript version of article $\underline{Y .}$ Xiao et al, Biomacromolecules 2020, 21 (1), 114-125

Assembly of Elastin-like Polypeptide Block Copolymers. Biomacromolecules 2012, 13 (5), 1598-1605.

[73] Pille, J.; van Lith, SA.; van Hest, JC.; Leenders, WP. Self-Assembling VHH-Elastin-Like Peptides for Photodynamic Nanomedicine. Biomacromolecules 2017, 18 (4), 1302-1310.

[74] Chen, TH.; Bae, Y.; Furgeson, DY. Intelligent Biosynthetic Nanobiomaterials (IBNs) for Hyperthermic Gene Delivery. Pharm. Res. 2008, 25 (3), 683-691.

[75] Le Fer, G.; Portes, D.; Goudounet, G.; Guigner, J.-M.; Garanger, E.; Lecommandoux, S. Design and Self-Assembly of PBLG-b-ELP Hybrid Diblock Copolymers Based on Synthetic and Elastin-Like Polypeptides. Org. Biomol. Chem. 2017, 15 (47), 10095-10104.

[76] Fujita, Y.; Mie, M.; Kobatake, E. Construction of Nanoscale Protein Particle Using Temperature-Sensitive Elastin-like Peptide and Polyaspartic Acid Chain. Biomaterials 2009, $30(20), 3450-3457$.

[77] Araújo, A.; Olsen, BD.; Machado, AV. Engineering Elastin-Like Polypeptide-Poly (ethylene glycol) Multiblock Physical Networks. Biomacromolecules 2018, 19 (2), 329-339.

[78] Tang, JD.; Caliari, SR.; Lampe, KJ. Temperature-Dependent Complex Coacervation of Engineered Elastin-like Polypeptide and Hyaluronic Acid Polyelectrolytes. Biomacromolecules 2018, 19 (10), 3925-3935.

[79] Jeannot, V.; Gauche, C.; Mazzaferro, S.; Couvet, M.; Vanwonterghem, L.; Henry, M.; Didier, C.; Vollaire, J.; Josserand, V.; Coll, JL.; Schatz, C.; Lecommandoux, S.; Hurbin, A. 
Author manuscript version of article $\underline{Y .}$ Xiao et al, Biomacromolecules 2020, 21 (1), 114-125

Anti-Tumor Efficacy of Hyaluronan-based Nanoparticles for the Co-Delivery of Drugs in Lung Cancer. J. Controlled Release 2018, 275, 117-128.

[80] Jeannot, V.; Mazzaferro, S.; Lavaud, J.; Vanwonterghem, L.; Henry, M.; Arboléas, M.; Vollaire, J.; Josserand, V.; Coll, JL.; Lecommandoux, S.; Schatz, C.; Hurbin, A. Targeting CD44 Receptor-Positive Lung Tumors Using Polysaccharide-Based Nanocarriers: Influence of Nanoparticle Size and Administration Route. Nanomedicine 2016, 12 (4), 921-932.

[81] Pickens, CJ.; Johnson, SN.; Pressnall, MM.; Leon, MA.; Berkland, CJ. Practical Considerations, Challenges, and Limitations of Bioconjugation via Azide-Alkyne Cycloaddition. Bioconjugate Chem. 2018, 29 (3), 686-701.

[82] Munneke, S.; Prevost, JR.; Painter, GF.; Stocker, BL.; Timmer, MS. The Rapid and Facile Synthesis of Oxyamine Linkers for the Preparation of Hydrolytically Stable Glycoconjugates. Org. Lett. 2015, 17 (3), 624-627.

[83] Munneke, S.; Hill, JC.; Timmer, MS.; Stocker, BL.; Synthesis and Hydrolytic Stability of N- and O-Methyloxyamine Linkers for the Synthesis of Glycoconjugates. Eur. J. Org. Chem. 2017, 25, 3722-3728.

[84] Ward, CC. ; Kleinman, JI. ; Nomura, DK. NHS-Esters as Versatile Reactivity-Based Probes for Mapping Proteome-Wide Ligandable Hotspots. ACS Chem. Biol. 2017, 12 (6), 1478-1483.

[85] Tanaka, H,; Kawai, T.; Adachi, Y.; Ohno, N.; Takahashi, T. $\beta(1,3)$ Branched Heptadecaand Linear Hexadeca-Saccharides Possessing an Aminoalkyl Group as a Strong Ligand to Dectin-1. Chem. Commun. 2010, 46 (43), 8249-8251. 
[86] Palma, AS.; Feizi, T.; Zhang, Y.; Stoll, MS.; Lawson, AM.; Díaz-Rodríguez, E.; Campanero-Rhodes, MA.; Costa, J.; Gordon, S.; Brown, GD.; Chai, W. Ligands for the $\beta$ Glucan Receptor, Dectin-1, Assigned Using “Designer” Microarrays of Oligosaccharide Probes (Neoglycolipids) Generated from Glucan Polysaccharides. J. Biol. Chem. 2006, 281 (9), 5771-5779.

[87] Tiwari, VK.; Mishra, BB1.; Mishra, KB.; Mishra, N.; Singh, AS.; Chen, X. Cu-Catalyzed Click Reaction in Carbohydrate Chemistry. Chem. Rev. 2016, 116 (5), 3086-3240.

[88] Thirumurugan, P.; Matosiuk, D.; Jozwiak, K. Click Chemistry for Drug Development and Diverse Chemical-Biology Applications. Chem. Rev. 2013, 113 (7), 4905-4979.

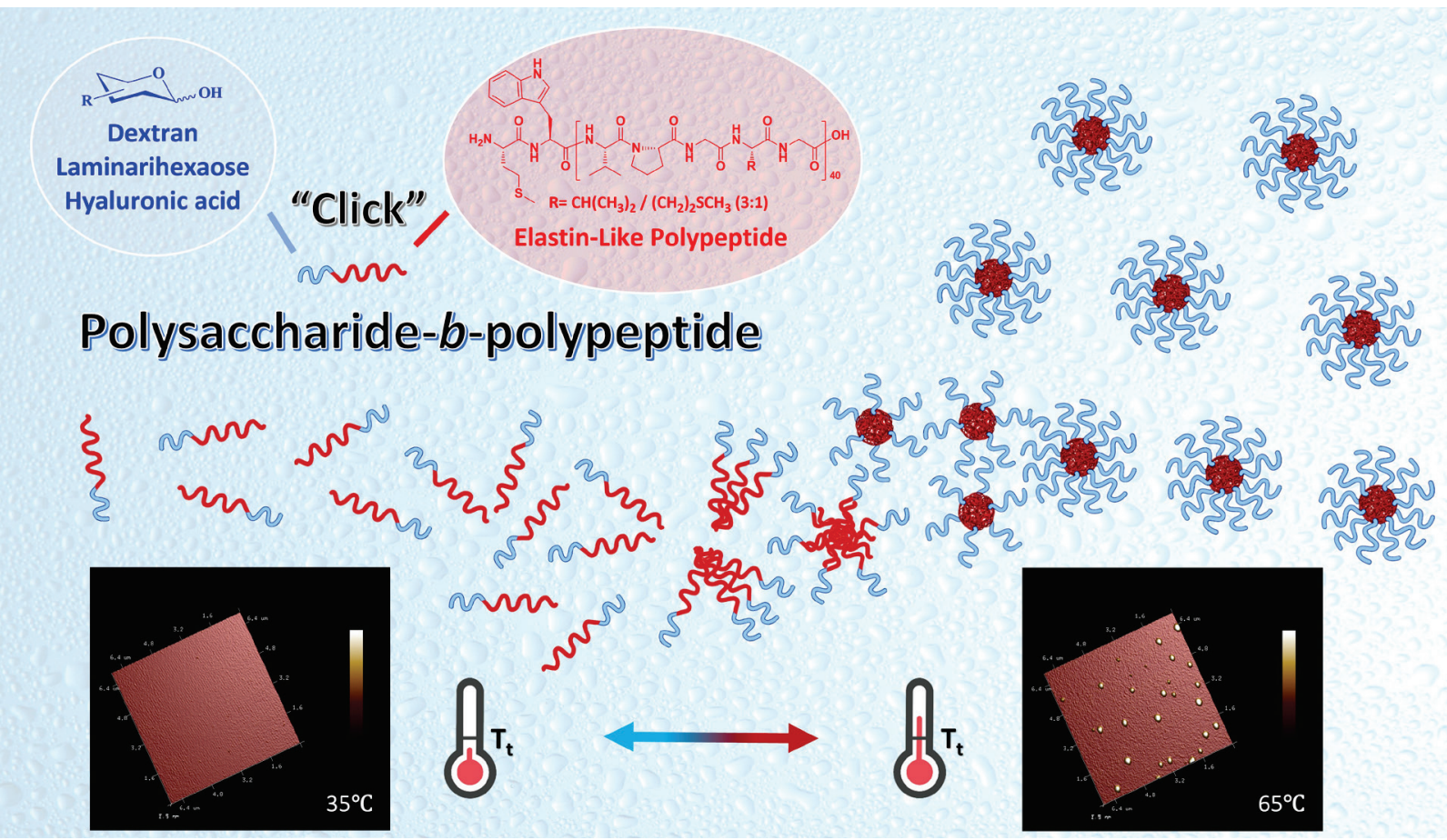

